\title{
Kritische Theorie: Kooperation
}

\author{
Kritik der bestehenden Philosophien plädiert nicht für das Verschwinden von \\ Philosophie oder gar ihren Ersatz durch Einzeldisziplinen wie die Sozialwissen- \\ schaft. Sie möchte formal und material eben jener Gestalt geistiger Freiheit helfen, \\ die in den herrschenden philosophischen Richtungen keine Stelle hat. \\ Theodor W. Adorno, Wozu noch Philosophie? (1962)
}

Die philosophische Erneuerung durch die Kritische Theorie unterscheidet sich von den philosophischen Erneuerungen durch die Phänomenologie und den Logischen Positivismus insofern, dass sie erst in der Mitte des 20. Jahrhunderts ausformuliert worden ist. Da jedoch die Schwerpunktverlagerung des Marxismus »hin zur Philosophie « (Anderson 1978 [1976]: 77), wie sie in den 192oer-Jahren an Georg Lukács und Karl Korsch sichtbar wird, für den Erneuerungsanspruch der Kritischen Theorie entscheidend ist, korrespondiert auch der Erneuerungsanspruch von Theodor W. Adorno und Max Horkheimer mit philosophieinternen Krisen, die an Alfred Seidels Bewußtsein als Verhängnis ablesbar sind. Analog zu den anderen beiden Kapiteln dieser Arbeit werden in einem ersten Teil diese Herausforderungen bzw. Krisen im Zusammenhang mit Seidel skizziert (5.1), um in einem zweiten Schritt die Erneuerungsstrategien der Kritischen Theorie an Lukács und Korsch (5.2) und darauf aufbauend an Adorno und Horkheimer (5.3) nachzuzeichnen.

\subsection{Herausforderung: Verlust gesellschaftlicher Legitimität}

Die Person Seidel und deren Text Bewußtsein als Verhängnis nehmen in diesem Kapitel einen etwas anderen Stellenwert ein als in den anderen beiden Kapiteln, da hier direkte philosophiehistorische Verbindungen bestehen: In der hier eingenommenen Perspektive ist zum einen die Verbindung zwischen Seidel und der Kritischen Theorie und zum anderen die Verbindung zwischen Seidel und derWissenssoziologie Karl Mannheims zentral. Beide Verbindungen werden im Folgenden näher umrissen. 


\title{
Weder Adorno noch Mannheim
}

Das Typoskript zu Seidels von Alfred Weber betreuter Dissertation Produktivkräfte und Klassenkampf - sie wurde 2008 posthum veröffentlicht (Seidel 2008) ${ }^{119}$ - zirkulierte seit 1922 in den intellektuellen Kreisen in Frankfurt am Main. »Seidel findet damit viel Zuspruch, findet überdies in Heidelberg Anerkennung und intellektuellen Anschluß (Velarde 2008: 180). Es handele sich bei seiner Dissertation um einen Versuch, eine Soziologie der Soziologie zu umreißen; der kritische Marxismus wird zum Gegenstand der Kritik (ebd.: 181). »Ich will nicht«, schreibt Seidel in seinem Vorwort, »die so beliebte Marx-Scholastik treiben, sondern die innere, den Denkern selbst oft nicht bewußte Struktur ihrer Gedanken zu erforschen suchen, vor allem aber die >petitiones principii<, deren es bei Marx eine Menge gibt« (Seidel 2008: 187). Als erste Referenz führt Seidel Lukács' 1921 erschienenen Aufsatz »Rosa Luxemburg als Marxist« an. Die enge Verbindung zu Lukács wird auch von Frese hervorgehoben: "Seidels Dissertation ist das früheste mir bekannte Echo auf Lukács' frühen Marxismus, der in breiteren Kreisen erst nach $1924 \mathrm{zu}$ wirken begann« (Frese 2001/02: 50-51).

Seidels Dissertation hat Spuren hinterlassen. »Hinweise auf eine Lektüre finden sich [...] bei Adorno, Benjamin, Sohn-Rethel und Löwenthal, diese beschränken sich jedoch auf die Nennung von Schlagworten, in aller Regel dem von der Metaphysik der Produktivkräfte« (Voller 2017: 72). Insofern Seidels Dissertation mit Lukács' Geschichte und Klassenbewußtsein (1923) als auch mit Karl Korschs Marxismus und Philosophie (1923) korrespondiert, habe er in seiner Dissertation erstmals Gedankengänge formuliert, die für die Argumentationsstrategien der Kritischen Theorie wegweisend waren.

\begin{abstract}
Stellt man in Rechnung, dass Seidels Arbeit zwar nicht gedruckt wurde, allerdings genau in jenem Milieu zirkulierte, aus dem sich die Kritische Theorie dann entwickelte, so wäre Produktivkräfte und Klassenkampf durchaus als eine Schrift zu begreifen, die zusammen mit Lukács' Geschichte und Klassenbewußtsein und Karl Korschs Marxismus und Philosophie einen frühen Einfluss auf die Gedankenentwicklungen ausübte, die dann zur Etablierung der Kritischen Theorie führten. (ebd.: 84)
\end{abstract}

Aus Seidel ließe sich, so sagt Jürgen Frese schon in den 1970er-Jahren, »leicht eine Vorgeschichte der >Kritischen Theorie〈 basteln [...], in der Seidel als deren mythischer Ahnherr figurieren würde [...]«(Frese 2001/o2: 47). Kurz: Die Kritik

119 Siehe Fn. 33. 
am Marxismus, die Seidel in Produktivkräfte und Klassenkampf formuliert, steht mit der Entstehung der Kritischen Theorie in einer direkten Verbindung. ${ }^{120}$

Seidels Dissertation allerdings scheint mir theoriegeschichtlich vor allem insofern von Interesse zu sein, als sie sehr früh [...] eine Kritik instrumenteller Technikauffassungen, marxistischer Fortschrittsgläubigkeit und schematischer Auslegung des historischen Materialismus vorschlug. Beide Ansätze sind zu Grundpfeilern kritischer Theoriebildung geworden, die sich in nahezu allen dem Umfeld der Gründungsgeneration des Instituts für Sozialforschung zuzurechnenden Arbeiten wiederfinden. (Voller 2017: 84)

Die philosophiehistorische Verbindung zwischen Seidel und der Kritischen Theorie wird durch ein weiteres schriftliches Zeugnis belegt, nämlich durch einen Brief Seidels an Adorno, datiert auf den 8. September 1922. Dieser einzig erhaltene Brief wurde 2017 von Christian Voller und Dirk Braunstein erstmals veröffentlicht. ${ }^{121}$ Unter anderem schreibt Seidel hier:

Warum muß der Mensch um seine Krankheit überwinden zu können, d.h. warum muß er zur Sublimierung sich ein falsches Bild von sich und der Welt, ja von seinem individuellen Ich sogar machen, warum muß er sich eine transcendente Welt erbauen, damit die Welt, das Leben und er selbst einen Sinn bekommt; warum darf er nicht immanent bleiben und das Leben an sich bejahen; oder warum kann er nicht mit einer untranscendenten Weltanschauung, nachdem er nun einmal d. Verruchtheit der Erkenntnis begonnen hat, leben. Die phänomenologische Aufzeigung durch den Untergang der Kulturen bei Verlust der einheitlichen transcendenten Findung genügt mir natürlich nicht, sondern ich muß das immanent-teleologische Warum wissen. (Voller/Braunstein 2017: 93-94)

Seidel begnügt sich nicht damit, den Verlust einer einheitlichen Transzendenz festzustellen, sondern möchte wissen, warum dies so ist. Die Antwort Adornos auf Seidels Frage kennen wir nicht. Gemäß Braunstein und Voller konnte nicht ermittelt werden, worauf Seidel in dieser und der folgenden Passage anspricht; in der hier eingenommenen Perspektive sind sie jedoch signifikant, auch wenn offen bleibt, warum sich Seidel gemäß seiner eigenen Selbstbeschreibung von Adorno »unterscheidet $\ll$.

120 Bereits Frese betont, dass es sich bei Seidels Texten um ein »Stück Geschichtsphilosophie« handele und nicht etwa um eine »lebensphilosophische Kulturtheorie« à la Ludwig Klages bzw. nicht um eine »Ontologie des Verhältnisses von Geist und Leben«, wie es eine oberflächliche Assoziation vermuten ließe (Frese 2001/o2: 52-53).

121 Der Brief umfasse im Original vier Seiten auf zwei Blättern, die Seidel »mit äußerst nachlässiger Handschrift gefüllt hat« (Voller/Braunstein 2017: 89). 
Es gibt gerade für Sie viel brennendere Probleme, aber Sie werden sie ja mehr als genug haben und unter ihnen eins, um das alle so gern herumgehen, nicht aus Ehrfurcht, wie es scheinen möchte, sondern aus - Feigheit. Und manchmal möchte es mir so scheinen, [als] ob alle anderen Probleme nur Ablenkung von diesem einzig zentralen Problem sind. Sie wissen ganz genau, was ich meine und worin wir uns ja unterscheiden. (ebd.: 9o-91)

Obwohl es eine Leerstelle bleibt, worin Seidel den Unterschied seiner eigenen Gedankengänge $\mathrm{zu}$ denen Adornos sieht, ist diese Passage bezeichnend. Viele seiner Zeitgenossen - so sagt Seidel - würden aus Feigheit bestimmte Probleme umgehen. Adorno hingegen stelle sich diesen Problemen, komme aber zu anderen Ergebnissen als er selbst. In Seidels Formulierung wird eine Art Pathos deutlich: Wo andere zu feige seien, seien Adorno und er selbst mutig genug, bestimmte Probleme zu artikulieren. Der Briefausschnitt macht deutlich, dass Seidel sein Denken einerseits in einer Verbindung zu Adornos Denken sieht, andererseits aber eine Differenz dazu herstellt. ${ }^{122}$

Wie erwähnt ist für Seidel auch die Verbindung zum Wissenssoziologen Karl Mannheim - er soll ihm besonders wohlgesinnt gewesen sein (Prinzhorn 1927: 2o) - zentral. Aber auch Mannheim - Georg Lukács' Mentor und Opponent der Kritischen Theorie - bietet Seidel offensichtlich keine befriedigenden >Lösungen<. Seidel und Mannheim haben sich um 1920 in Freiburg kennengelernt. Mannheim war damals Privatdozent in Heidelberg, Seidel stand am Ende seiner Promotion (Frese 2001/2002: 51). Wie Mannheim soll sich auch Seidel für eine Soziologie der Intelligenz interessiert haben. »Viele Passagen in den frühen programmatischen Arbeiten von Mannheim lesen sich wie Reminiszenzen an die zahlreichen Diskussionen, die er mit Seidel über Ideologie, Utopie und Intelligenz führte « (ebd.). ${ }^{123}$ Wo Mannheim jedoch dezidiert feststellt, dass eine »Soziologie des Geistes « nun als eine »eindeutig formulierbare und in Einzelheiten erforschbare Fragestellung «(Mannheim 1929:40) auftauche, hadert Seidel - wie gezeigt - mit solchen programmatischen Ansagen, da die Fragen nach der Letztbegründung eines soziologischen Standpunkts für ihn gewissermaßen nicht zu Ende gedacht sind. »Die Gesellschaft selbst kann wohl nur zum Problem werden, wenn sie selbst problematisch geworden ist, wenn sich ihr organischer Zusammenhang aufzulösen beginnt. - Dies wäre der Grundgedanke zu einer »Soziologie der Soziologie« (Seidel 1927: 174).

122 Voller beginnt seinen Aufsatz mit der Anekdote, wonach Adorno in einer Vorlesung von 1965 an seinen »verstorbenen Jugendfreund namens Seidel« erinnert, der den Begriff der »Metaphysik der Produktivkräfte« in die Kritik des Marxismus eingeführt habe (Voller 2017: 6o).

123 Frese weist nicht aus, woher er diese Information hat. 
Mannheim hingegen war - wie das folgende Beispiel zeigt - von der Möglichkeit einer >Soziologie des Geistes< überzeugt. In seiner Rede Die Bedeutung der Konkurrenz im Gebiete des Geistigen, die Mannheim 1928 am 6. deutschen Soziologentag in Zürich gehalten hat, wird dies exemplarisch deutlich. Mannheim stellt das Thema der Konkurrenz in diesem Vortrag nicht nur »als Phänomen der ökonomischen Sphäre« (Mannheim 1929: 39) zur Debatte, sondern er betrachtet Konkurrenz »als Phänomen des gesamten gesellschaftlichen Lebens « (ebd.). Er möchte die Konkurrenz also dort aufweisen, »wo sie bisher am wenigsten beobachtet wurde: im Gebiete des geistigen Lebens in ihrer konstitutiven Bedeutung [...] (ebd.). Mannheim macht hier zweierlei: Erstens bestimmt er das »geistige Leben« als etwas Gesellschaftliches, und zweitens verknüpft er dieses mit Konkurrenzverhalten. Er stellt fest:

Um das Wichtigste dieses denksoziologischen Tatbestandes hervorzuheben denksoziologisch, wenn man den historischen Gesamtzusammenhang stets im Auge hat -, kämpfen eigentlich gar nicht Erkenntnistheorien gegen Erkenntnistheorien, wie es zunächst den Anschein hat, sondern je daseiende verschiedene Denkweisen, Paradigmata gegeneinander, die durch die dazugehörigen Erkenntnistheorien erst legitimiert werden sollen. Im historisch-sozialen Zusammenhang sind Erkenntnistheorien nur vorgeschobene Posten im Kampfe der Denkstile. (ebd.: 81)

Werden Erkenntnistheorien in einen historischen und sozialen Kontext gestellt, seien sie also lediglich vorgeschobene Posten, d.h. Wächter für Denkstile.124 Nicht auf der Ebene von Erkenntnistheorien werden weiterführende wissenschaftstheoretische Einsichten gewonnen - so die Implikation -, sondern auf der Ebene von Denkstilen. Diese Aussage hinterfragt den Wahrheitsgehalt von Erkenntnistheorien auf einer prinzipiellen Ebene und eröffnet Perspektiven, die das Denken und die Philosophie wissenssoziologisch wenden. Mannheims Vortrag galt, so stellt der Historiker Reinhard Laube fest, sofort als spektakulär und erhitzte die Gemüter (Laube 2004: 519/521). »Die wissenssoziologische Fragestellung bedroht die vermeintlich festen Bastionen hierarchisierter Beobachtungsverhältnisse $[\ldots]$ (ebd.: 520).

Mannheim ging als einer der >Gründerväter der Wissenssoziologie in die Wissenschaftsgeschichte ein. In seinen eigenen, programmatischen Worten: »Auf die Spitze getrieben und auf eine prägsame Formel gebracht, das Problem einer Soziologie des Geistes taucht als eine eindeutig formulierbare und in Einzelheiten erforschbare Fragestellung auf« (Mannheim 1929:

124 Mannheim soll als erster Ludwik Flecks Begriff des »Denkstils« in seinem Aufsatz »Das Problem einer Soziologie des Wissens« (1925) rezipiert haben (Sauerland 2017: 42, Fn. 11). 
40). Diese Aussage enthält eine Setzung, die zugleich eine Ausgangslage für wissenssoziologische Fragestellungen schafft: die Möglichkeit, Erkenntnisse aus einer soziologischen Perspektive zu untersuchen. ${ }^{125}$ Für Seidel hingegen schien Mannheims Standpunkt zu kurz gegriffen zu sein, da die »Soziologie des Geistes « zwar geistige Produkte als etwas Gesellschaftliches bestimmt, nicht aber das Problem löst, das daraus folgt: Wie soll damit umgegangen werden, dass genau diese, d.h. die eigenen Gedanken gesellschaftlich bestimmt und dadurch möglicherweise verfälscht sind? Seidels Versuch einer »Soziologie der Soziologie « wollte die kognitive Perspektive des (marxistisch) Fragenden nicht außer Acht lassen (Velarde 2008: 181). »Wie dann aber erkennen, wenn die eigene Perspektive der fundamentalen Kritik unterzogen wird und sie zu einem verzerrten Bewußtsein führe?«(ebd.).

Wie deutlich geworden ist, schließt sich Seidel bereits in seiner Dissertation weder einer "parteiorthodoxen « noch einer "pragmatischen « Lesart des Marxismus im Sinne der Wissenssoziologie Karl Mannheims an (Velarde 2008: 181). »Zwischen beiden Perspektiven gab es keinen >goldenen< Mittelweg. Seidel schlug einen eigenen, in den Abgrund führenden Weg ein. Der Ansatz ging zu weit, um >rational< ausbaufähig zu werden, erstickte in sich selbst, selbst wenn man Seidel als >Geheimtip < der deutschen Wissenssoziologie betrachtete (ebd.: 182). ${ }^{126}$

Wie sich Seidel bei seinem Versuch einer »Soziologie der Soziologie « gedanklich verheddert - warum er sich also keinem der zeitgenössischen Theorieangebote letztgültig anschließen konnte oder wollte -, soll im Folgenden an konkreten Textstellen aus Bewußtsein als Verhängnis nachgezeichnet werden. Dabei wird gleichzeitig eine u.a. durch die Soziologie ausgelöste Krise für die Philosophie ersichtlich: Wie kann der eigene wissenschaftliche Erkenntnisstandpunkt noch legitimiert werden, wenn der Geist durchweg von sozialen Strukturen bestimmt wird?

125 Diese Rolle kommt bei Mannheim der »freischwebenden Intelligenz« zu. »Ihr Ziel müsse sein, die vorreflexiven Denkvoraussetzungen aller partikularen Anschauungen ins Bewusstsein zu heben und den Grund für diese Evidenz zu zeigen« (Maasen 20og: 26; siehe auch Fn. 129).

126 Die Quellen dieses Gerüchts sind laut Frese Peter Christian Ludz und Kurt Lenk (mündlich 1968). Dass Seidel - in gewissem Sinne bis heute - als »Geheimtip« (Frese) gilt, wird durch das Gerücht gestützt, dass Adornos Fangfrage in Bezug auf die Wissenssoziologie stets gelautet haben soll: Kennen Sie Seidel? (vgl. auch Frese 2001/2002: 62, Fn. 3). 


\section{Erstarren vor der Kompliziertheit, Ekel vor der Banalität, Versinken im Relativismus}

In Seidels Schrift fehlen im Unterschied sowohl zu Mannheims als auch Adornos bzw. Horkheimers Schriften programmatische Aussagen über ein neues Forschungsfeld sowie rhetorische Wendungen, die seine eigenen Gedanken als wissenschaftlich, gesellschaftlich oder politisch relevant ausweisen. Im Gegenteil denkt Seidel nebst der 〉Psychologisierung` des Geistes wie sie vor allem am Beispiel von Husserl deutlich geworden ist - konsequent auch die >Soziologisierung < des Geistes radikal weiter: Was bedeutet es für das (eigene) Denken, wenn das Bewusstsein als von sozialen Strukturen bestimmt gedacht wird? Seidel will keine Antworten auf diese Frage geben, vielmehr durchdenkt er die Konsequenzen dieser Problematik.

»Im allgemeinen «, schreibt er, »handelt der Mensch ohne nähere Untersuchung der psychischen und sozialen Bedingungen, in denen er lebt « (Seidel 1927: 118). Würden diese Bedingungen aber bewusst gemacht, könnten drei Folgen eintreten: das Erstarren vor der Kompliziertheit, der Ekel vor der Banalität und das Versinken im Relativismus (ebd.: 118-124). Im ersten Fall könne die Bewusstheit psychischer und sozialer Vorgänge zu »Hemmungen des Handelns « führen. »Rationalisten glauben [...], die sogenannte Blindheit des instinktiven Handelns durch den Überblick und die Klarheit des Bewusstseins zu überwinden und so ein zweckmäßiges Handeln zu ermöglichen« (ebd.: 118-119). Jedoch verleite der »überschwengliche Glaube an die Allmacht des Wissens [...] zu Fehlgriffen« (ebd.: 119). Als »typischen Fall« bezeichnet Seidel hier Marxisten, »die auf Grund von Wissenschaft oder vielmehr Theorie Politik treiben wollen« (ebd.). Dass Marxisten »so geringen Erfolg haben«, führt er darauf zurück, dass »sie zu viel erkannt haben« (ebd.). Im zweiten Fall führt die Bewusstmachung psychischer und sozialer Zusammenhänge zu einem Ekel vor der Banalität. Wo der erste Punkt insbesondere soziologisches Wissen betrifft, betrifft dieser zweite psychoanalytisches:

Beginnt einmal diese psychologische »Selbst- und Fremdzerfleischung «, so wird sie so leicht kein Ende finden [...]. Steigt man in die Abgründe des Unbewußten hinab, so vergeht oft jeder Schimmer des Wertes, der vorher alles Tun umstrahlte. [...] Wenn wirklich die in rücksichtsloser Analyse gefundenen Motive, seien es nun Machtgier oder Sexualität, die bestimmenden sind, so bedeutet das für die Einzelnen, daß sie bisher in Illusionen gelebt haben. (ebd.: 120)

Die Bewusstwerdung, dass die eigenen Motive mit Macht und Sexualität verstrickt sind, würden »Wahrheitsfanatiker begrüßen«, doch für »Menschen, die unter illusionären Wertungen und Weltbildern ihr Leben aufgebaut haben«, bedeute sie eine »schwere Erschütterung, vorausgesetzt, daß sie die Richtigkeit 
und Bedeutung der Analyse zugeben und sie nicht einfach als unsinnig oder belanglos abweisen [...] «(ebd.).Zum Beispiel müsse allein die religionspsychologische »Andeutung, daß zwischen der Ekstase der Heiligen und sexuellen Erregungszuständen Beziehungen bestehen, [...] einen Katholiken aufs tiefste verletzen« (ebd.: 121). Die gleiche Desillusionierung jedoch könne »bei allen geistigen Leistungen eintreten, sobald sie dem Prozeß der Analyse unterworfen werden « (ebd.). Wahrscheinlich - so bringt Seidel seinen Gedankengang auf den Punkt - geschehen »die wertvollsten Leistungen [...] unter illusionären Vorstellungen« (ebd.). Er behauptet hier, dass die Bewusstmachung psychoanalytischer und soziologischer Vorgänge eine geistige Leistung sei, dass aber genau diese Leistung wiederum die geistige Produktivität hemmen bzw. zerstören könne. Im dritten Fall - Versinken im Relativismus -, der wiederum die Soziologie fokussiert, führe das Bewusstsein psychischer und sozialer Zusammenhänge zu einer Erschütterung des Weltbildes. Hier bringt Seidel allgemeine Fragehorizonte seiner Zeit gewissermaßen auf den Punkt. Der Prozess der Selbstanalyse führe

zur Einsicht, daß Charaktereigenschaften durch Klasse und Volk mitbedingt sind. Man erkennt die Abhängigkeit einer politischen Wertung von der eigenen Klassenlage und gibt bei einiger Ehrlichkeit zu, daß man andere Staatsund Gesellschaftsideale hätte, wenn man in einer anderen Klasse geboren wäre. Völlig relativiert wird eine Weltanschauung durch den Vergleich mit anderen historischen Epochen. Die Überzeugung, daß alle Meinungen und Empfindungen, sogar die Ergebnisse der exakten Wissenschaft, einem räumlich und zeitlich begrenzten Kulturkreise angehören, legt den Schluß nahe, daß auch die eigene Weltanschauung nur Ausdruck einer Zeitepoche ist, daß auch sie überholt werden wird, wie so manche Auffassung, die mit Emphase als letzte Wahrheit verkündet wurde. (ebd.: 122)

Die Wendung, die Seidel hier nimmt, ist symptomatisch für die Formulierung seiner Gedanken: seine Überzeugung, dass Wahrheitsansprüche - auch die eigenen - immer ausgehend von einer spezifischen historischen und sozialen Situation formuliert werden, bestimmt weitgehend seine Problematisierungen. Das Erstarren vor der Kompliziertheit, der Ekel vor der Banalität und das Versinken im Relativismus erscheinen in seinen Überlegungen als Folgen eines Bewusstseins, das den eigenen Wahrheitsanspruch gnadenlos seziert. ${ }^{127}$

127 Wie bereits angedeutet, wird Seidels Nähe zu Nietzsche an vielen Textstellen deutlich. Unter der Überschrift »Schopenhauer, Nietzsche und ich « grenzt Seidel seine eigene Position explizit von derjenigen Nietzsches und Schopenhauers ab: »Ich: Das Leben ist zu verneinen, wie bei Schopenhauer, aber um des Lebens willen und zwar des nicht 
Die hier beispielhaft zitierten Stellen deuten die Verbindung zwischen Marxismus und Psychoanalyse an, die für Seidels Gedankengänge - wie auch für die Ausformung der Kritischen Theorie - bestimmend ist:

Kultur, so referiert er [Seidel, MD] in Bewußtsein als Verhängnis den »Forschungsstand « seiner Zeit, bedeute wesentlich Sublimierung, Verdrängung und Umweg: Sublimierung des hypertrophierten Sexualtriebs, Verdrängung des produktiven Grundes kapitalistischer Vergesellschaftung im kulturellen Überbau und Umwege auf dem Weg zu Zielen, die in letzter Instanz der Wille zur Macht setze, wie Nietzsche ihn interpretiert hatte. (Voller 2017: 75)

Verdrängte Triebenergien äußern sich für Seidel also auf einer gesellschaftlichen Ebene - entweder als Sublimierung oder Neurosen, wobei beides nicht eindeutig zu unterscheiden sei. ${ }^{128}$ Analysen können Sublimierungen und Neurosen zwar auflösen, gleichzeitig würde dabei aber auch die Kultur aufgelöst. »Die unter Seidels Zeitgenossen verbreitete Angst, durch die psychoanalytische Methode von bestimmten Neurosen zwar geheilt, seiner Potentiale und Kreativität jedoch genau dadurch beraubt zu werden, wird somit auf das Feld des Gesellschaftlichen transponiert« (ebd.: 76). Laut Seidel kann die moderne Wissenschaft diesen Vorgang eines möglichen Kulturzerfalls zwar analytisch durchschauen, eine Veränderung oder eine Durchbrechung des »blinden Triebes« entziehe sich aber der modernen Ratio. Denn »auch das reflektierende Bewußtsein [...] hat nur auflösende Wirkung, weil es immer wieder in den Mittelpunkt einer Persönlichkeit gestellt und damit Selbstzweck wird. Dann verfängt sich das Leben in der Reflexion «(Seidel 1927: 97).

Seidels Überlegungen zur Reflexion als Selbstzweck sind im hier vorgestellten Zusammenhang zentral. »Es gibt aber auch Menschen, die über das Reflektieren nicht hinauskommen [...]. Das müssen wir dann aber als Symptom einer an sich gehemmten Persönlichkeit auffassen, die man im stärkeren Grade als psychopathisch bezeichnen könnte« (ebd.: 99-100). In

gesteigerten Lebens, sondern des harmonischen, ruhigen, in Gemeinschaft gebundenen. Das übersteigerte Leben heißt der Tod « (Seidel 1927: 219). »So ist Nietzsches Position im Unterschied zu der meinigen eine Ablehnung der Gemeinschaft und der Religion aus Bejahung des Willens zur Macht und (bei der Gleichsetzung beider auch) aus Lebensbejahung« (ebd.: 218).

128 »Diese verdrängten Triebenergien können sich in Phänomenen auswirken, die nach Freud teils als Neurosen, teils als Sublimierungen bezeichnet werden. Die Unterscheidung ist in concreto schwer zu treffen: man könnte einzelne Kulturphänomene mehr als Neurose, denn als Sublimierung ansprechen, es kommt oft nur auf die Umstände an und ist wohl überhaupt nur eine Frage der Wertung « (Seidel 1927: 96). 
der psychiatrischen Literatur trete diese Erscheinung unter dem Namen des »Grübelzwanges« auf (ebd.: 100). Der Subtext von Seidels Überlegungen ist auch hier - wie es im Kapitel über Husserl deutlich geworden ist - eine Analyse des Typus des Wissenschaftlers. Solche »dauernd gehemmte[n] Typen« seien natürlich zu jeder Zeit möglich, sie werden aber »in bestimmten Epochen ganz besonders stark vertreten sein « (ebd.). In Zeiten, in denen es »bindende Weltbilder« gibt, in denen die »Illusions- und Glaubensfähigkeit stärker, wo die Ernüchterung noch nicht an jeder Häuserfassade zu spüren ist [...], sind diese Menschen eingebettet in den Kreis der gebundenen Gemeinschaft« (ebd.). In individualistischen Zeiten hingegen sei »jeder auf sich selbst angewiesen, und somit werden diese Typen sich in ihrer privaten Reflexion verfangen und bei der bestehenden Meinungsfreiheit sie zur öffentlichen erheben" (ebd.: 100-101). Lapidar fügt Seidel an: »Man glaubt dann noch mit ihrer Hilfe alles verbessern zu können, indem man selbst an ihr zugrunde geht « (ebd.: 101). »Der aktive Psychologe oder Gelehrte kann sich zwar dadurch retten, daß er die Erkenntnisse der Reflexion gestaltet oder verwendet, daß er sie also in Tätigkeit umsetzt und sich so von ihnen befreit. Die Reflexion wird ihm dadurch zum Mittel. Zum leeren Selbstzweck wird sie nur dem, der um diese letzte Rettung nicht weiß, der in der Reflexion gefangen bleibt« (ebd.: 97).

Letztlich gelte es, diesen Typus des Analytikers in sich selbst aufzulösen, indem man die »Analyse gegen die Analyse « treibe. Dieser neue »Typus" wiederum müsse »auf Grund seiner Wesensveranlagung aus innerer Notwendigkeit negativ sein, aber gegen die Negativität, nihilistisch gegen den Nihilismus « (ebd.: 204). Jedoch wird selbst die Nihilisierung des Nihilismus es klingt hier deutlich Hegels Modell der »Negation der Negation « an - von Seidel durch eine reflexive Schleife gezogen:»Aber - ist das keine pragmatische Verzweiflung mit einem Schielen auf ihre möglichen positiven Wirkungen? [...] Läuft aber nun dieser gegen den eigenen Typus gerichtete Kampf nicht darauf hinaus, den Teufel durch Beelzebub zu vertreiben « (ebd.)? In den letzten Sätzen seines Manuskripts legt Seidel nahe, dass selbst eine »Analyse der Analyse « lediglich sichtbar mache, dass die Wirkungen des Bewusstseins verhängnisvoll sind. »Nur der Analytiker, nur derjenige, der in der Reflexion positiv sein zu können glaubt, wird sich in sie [die Reflexion, MD] hinein vertiefen und sie wird ihn erläutern (?) [sic!] soweit er ehrlich ist, und dann möglicherweise negativ auf ihn wirken, d.h. ihm seinen Glauben an die Wirkungen des Bewußtseins erschüttern. Und das wäre der schönste Erfolg « (ebd.: 205). An dieser Stelle wird die Grenze sichtbar, vor der Seidel - im Unterschied sowohl zu Adorno und Horkheimer als auch Mannheim - keinen Halt macht: $\mathrm{Er} »$ rettet« sich in keinen Zweck, sondern führt selbst die »Analyse der Analyse« analytisch ins Bodenlose. 


\section{Selbstreflexiver Kollaps}

Aus Seidel ließe sich, so sagt Jürgen Frese schon in den 1970er-Jahren, »leicht eine Vorgeschichte der >Kritischen Theorie< basteln [...], in der Seidel als deren mythischer Ahnherr figurieren würde [...] (Frese 2001/o2: 47). Jedoch gebe es einen Differenzpunkt, der Seidel nicht nur von Adorno, sondern auch von anderen >kritischen Theoretikern ₹ wie Horkheimer, Bloch, Benjamin, Kracauer, Sohn-Rethel, Marcuse und Fromm unterscheide: »Seidels Selbstkritik der sich durchschaut habenden Aufklärung macht vor sich selbst nicht halt und lässt kein geschichtsphilosophisches Reservat für den kritischen Kritiker übrig: Auch Seidels Buch ist noch Symptom und Beschleunigungsmoment eines Verfallsprozesses - und nicht Herr seiner eigenen Wirkungen« (ebd.: 61). Wo genau, so muss gefragt werden, liegt dieser Punkt, vor dem Seidel nicht haltmacht - die Begründer der Kritischen Theorie aber sehr wohl? Und wie lässt sich davon ausgehend die Krise beschreiben, die Seidel sichtbar macht?

Seine Rückbezüge auf die Wissenschaft bzw. den Typus des Wissenschaftlers und insbesondere seine Reflexionen auf sich selbst als Forschender sind diesbezüglich erhellend. »Der Wissenschaftler«, so stellt er mit seinem üblichen Bezug auf psychologische und psychoanalytische Denkmodelle fest, »ist ein sublimierender Perverser« (Seidel 1927: 212.).

Gerade die Wissenschaftler haben es so nötig, den Wert ihrer Erkenntnisse zu betonen, da sie eben die entgegengesetzte Wirkung haben, was sie vor sich nicht wahr haben wollen, da sie de facto die Wissenschaft um anderer Motive willen betreiben, welche besonders bei der »Wissenschaft« um ihrer selbst willen« zu verdecken sind - aus Wahrheitssadismus und Machtstreben. (ebd.: 212)

Wird der Wissenschaftler sich der psychologischen und soziologischen Motive der eigenen Tätigkeit bewusst - so implizieren Seidels Ausführungen -, wird deutlich, dass Wahrheitssadismus und Machtstreben die Motive dieser Arbeit sind. Im Unterschied etwa zu Mannheim, der die wissenschaftliche Tätigkeit als solche objektiviert, ${ }^{129}$ bezieht Seidel zugleich seinen eigenen Standpunkt als Wissenschaftler in seine Analysen mit ein. Daraus resultiert seine Diagnose, dass Machtstreben, Sexualität und Wahrheitssadismus für die Wissenschaftsproduktion wesentliche Antriebe sind, dass Wissenschaftler diese Motive aber verdecken, da ansonsten Erkenntnisse ihren Wert verlieren.

129 Mannheim löst das Problem, in das sich Seidel verstrickt, mit dem von Alfred Weber geprägten Terminus der »frei schwebenden Intelligenz«: Den Angehörigen der >frei schwebenden Intelligenz` gelinge es eher als anderen Gruppen, sich von der Ideologiehaftigkeit des Wissens zu befreien. Die »frei schwebende Intelligenz« sei also eine relativ klassenlose Schicht, die gebildeter, sozial ungebundener und unvoreingenommener im Hinblick auf spezifische Interessen ist (Maasen 2009: 25). 
Die Krise, die hier deutlich wird, betrifft die Legitimation des eigenen philosophischen Standpunkts. Wenn sichtbar wird, dass der eigene Erkenntnisstandpunkt mit der je eigenen sozialen Situation zusammenhängt, kommt auch die Annahme eines absoluten, von sozialen Faktoren unabhängigen Geistes in Bedrängnis. Welche Bedeutungen haben Erkenntnisse, wenn sie durch Kategorien wie »Klasse«, »Volk« und »Kultur « formiert werden? Seidel nimmt sich wie gesagt nicht aus dieser Diagnose aus. Auch er selbst gehöre zu »diesem Typus der analytischen Wissenschaftler, der Wahrheitssadisten «, ja, er sei »davon ein ausgesprochener Typ« (Prinzhorn 1927: 31). Er nimmt den Terminus der Selbstkritik bzw. Selbstreflexion in radikaler Weise ernst und konfiguriert Selbstkritik nicht abstrakt als Möglichkeit oder Modus philosophisch-denkerischen Schaffens (wie es weiter unten in Bezug auf die Kritische Theorie deutlich wird), sondern wendet sie, gewissermaßen ungefiltert, auf sich selbst und auf seinen eigenen Schaffensprozess an. Der Einsatz seiner Analysen sei - so pointiert Voller - sein eigenes Denken und Leben: »Indem er rational gegen die Ratio zu Felde zog - >auf eine Weise, die es sich etwas kosten ließ<, wie Bloch anmerkte -[,] machte der Theoretiker Seidel allerdings stets den ganzen Menschen Seidel zum Einsatz seiner intellektuellen Gefechte« (Voller 2017: 79). So analysiert er die »Ideologien der Gegenwart«130 ausgehend von seinen eigenen Erfahrungen. In Vollers Worten:

Jugendbewegung, Psychoanalyse, Marxismus und revolutionärer Sozialismus, reaktionäre Kulturkritik und verschiedene ästhetische Strategien und Avantgarde-Bewegungen der 1920er Jahre werden als durchlebte und durchschaute Stationen des eigenen Lebens- und Denkweges analysiert. Durchweg macht Seidel damit die eigene Erfahrung - und das bedeutet in erster Linie die Leiderfahrung des (drohenden) Wahnsinns und die daraus resultierende Position des Außenseiters - zur Grundlage einer Methode, die objektive Einsichten durch radikalen Subjektivismus ermöglichen soll. (ebd.: 82)

Der »radikale Subjektivismus«, der in den fahrigen und (selbst-)kritischen Skizzen erkennbar ist, wird von Seidel selbst allerdings in keiner Weise zum Programm erhoben oder als Lösungsstrategie vorgestellt. Vielmehr wird dieser Subjektivismus in der permanenten Selbstreflexion greifbar, die sich im Text zuweilen fast verselbstständigt. Es ist darum die Art und Weise, wie Seidel beständig und teilweise zirkulär seine selbstreflexiven Denkbewegungen ausformuliert, die diesen Subjektivismus so radikal erscheinen

130 Wie bereits angesprochen diskutiert Seidel in diesem Zusammenhang den »MarxismusSozialismus«, die »Neuromantik« (die Gemeinschaft, die Religion, das Kulturgewollte, die Ideologie der Natürlichkeit, das Erlebnis, die Frauenbewegung), den »Nationalismus«, den »Pazifismus« und die »Untergangsidee« im Sinne Oswald Spenglers (Seidel 1927: 166-202). 
lässt. Selbst sprachlich wird der finalen Erkenntnis und der absoluten Wahrheit kein Refugium mehr eingeräumt. Die doppelte Negation wird nicht in die Affirmation aufgelöst. Sie stellt lediglich eine Drehung in einem fatalen denkerischen Reigen dar, der in der unablässigen Bewusstwerdung und Infragestellung der eigenen existenziellen und auch theoretischen Position nie zum Stillstand kommt.

Es ist diese Nähe zu den eigenen Denkbewegungen, die verhindert, dass der Text Bewußtsein als Verhängnis insgesamt als kulturpessimistisches Pamphlet erscheint. »Was sie [die (selbst-)kritische Skizze, MD] jedoch davor feit, sich in tragischer Spekulation gänzlich zu verlieren und ihre analytische Schärfe über alle Fahrigkeit hinweg verbürgt, ist die Nähe, aus der sie geführt wird. Durch die Lehren, die er so unnachgiebig seziert, ist Seidel selbst gegangen « (Voller 2017: 82). Er denkt nicht in Mustern möglicher akademischer Profilierung, er denkt so könnte pointiert werden - um des Denkens willen. Seine Reflexionen und Selbstreflexionen über das Bewusstsein machen keinen Halt vor der eigenen Position und verfangen sich in einem Circulus vitiosus. Weder synthetisiert er seine Gedankengänge, noch löst er sie auf. Philosophische Lösungserwartungen werden dadurch nicht befriedigt: In philosophischer Hinsicht kollabieren seine Analysen gewissermaßen infolge der eigenen Selbstkritik.

Seidels Gedankengänge, die sich jedem strategischen Denken entziehen, verdeutlichen, dass angesichts soziologischer und psychoanalytischer Theorien die Legitimität philosophischer Positionen fundamental herausgefordert wird: Wie lässt sich ein philosophischer Standpunkt sui generis rechtfertigen, wenn der Geist maßgeblich aus gesellschaftlichen Strukturen besteht und durch die Sublimationen von Triebenergien bestimmt wird? Wie lässt sich wissenschaftliche Tätigkeit legitimieren, wenn klar ist, dass der Geist weitestgehend ein gesellschaftliches Produkt ist? Die Frage, wie es Adorno und Horkheimer gelingt, ausgehend von solchen Herausforderungen einen philosophischen Erneuerungsanspruch argumentativ zu formulieren, ist vor dem Hintergrund von Seidels Bewußtsein als Verhängnis signifikant. Wie gehen sie es an, Selbstkritik zum Programm einer philosophischen Erneuerung zu erheben, ohne in das geschilderte Dilemma zu geraten?

\section{Thesen und Vorgehen}

Die Geschichtsschreibung der Kritischen Theorie beginnt mit der »Marxistischen Arbeitswoche«, die an Pfingsten 1923 in einem Bahnhofshotel in Thüringen stattgefunden hat. ${ }^{131}$ Unter den rund 20 Personen, die an dieser

131 »Unter den Teilnehmern waren noch nicht diejenigen, deren Namen später mit der Kritischen Theorie identifiziert werden sollten, wie Horkheimer, Adorno und Marcuse, sondern vor allem politisch aktive Wissenschaftler, wie Korsch und Wittfogel, außerdem 
informellen Konferenz teilgenommen haben, ${ }^{132}$ befinden sich auch Georg Lukács und Karl Korsch. ${ }^{133}$ Korschs Manuskript seines bekannten Aufsatzes Marxismus und Philosophie soll die Textgrundlage für die Diskussionen auf dieser Tagung gewesen sein. ${ }^{134}$ Die Tatsache, dass die beiden Autoren, die nebst Antonio Gramsci - als Begründer des sogenannten >westlichen Marxismus gelten, ${ }^{135}$ bei der Initialveranstaltung der Kritischen Theorie anwesend gewesen sind, trägt für sich symptomatische Züge - aber auch für die Argumentation des vorliegenden Kapitels: Sie verweist auf die Kontinuitäten zwischen der keineswegs homogenen Gruppe von Intellektuellen, die sich in den 1920er-Jahren um eine Neuinterpretation von Marx' Schriften bemüht hatten, und den wenig später initiierten theoretischen Ansätzen der Kritischen Theorie, wie sie vor allem mit den Namen Horkheimer und Adorno verbunden sind (insbesondere dazu: Fracchia 1987). Wie Martin Jay betont, äußerten sich das Institut für Sozialforschung und Lukács »von der Basis einer gemeinsamen Tradition aus zu denselben Problemen«(Jay 1981 [1973]: 211).

z.B. Richard Sorge und Friedrich Pollock, und schließlich Georg Lukács« (van Reijen 1984: 24). "Während der EMA [Ersten Marxistischen Arbeitswoche, MD] war Weil [Felix Weil, MD] die Idee einer festeren Institution gekommen; verschiedene Freunde an der Frankfurter Universität bestärkten ihn darin, und in gemeinsamen Überlegungen kristallisierte sich rasch eine klare Vorstellung davon heraus« (Jay 1981 [1973]: 24). Siehe auch: Wiggershaus 1986: 25-26; Buckmiller 1988. Offiziell gegründet wurde das Institut 1923: »Die offizielle Gründung des Instituts fand am 3. Februar 1923 aufgrund einer Verfügung des Kultusministeriums statt« (Jay 1981 [1973]: 28).

132 Die Teilnehmenden bestanden hauptsächlich aus (Ehe-)Paaren: Christiane und Richard Sorge, Hedda und Karl Korsch, Käthe und Felix Weil, Rose und Karl August Wittvogel, Friedrich Pollock, Gertrud und Ludwig Alexander (inklusive Kind), Konstantin Zetkin, Georg Lukács, Hede Massing und Julian Gumperz, Margarete Lissauer und Béla Fogarasi, Karl Schmückle und Fukumoto Kazuo.

133 Korsch gilt als »geistige[r] Initiator« der Marxistischen Arbeitswoche (Buckmiller 1988: 156).

134 »Es wurde diskutiert über Korschs `Marxismus und Philosophie` und es war die erklärte Absicht der Diskussionsrunde, die verschiedenen Marxauffassungen, die damals existierten, auf eine gemeinschaftliche Basis zu stellen« (van Reijen 1984: S. 24). »Den größten Teil der Zeit verbrachte man mit der Diskussion von Korschs noch nicht veröffentlichtem Manuskript >Marxismus und Philosophie« (Jay 1981 [1973]: 23). Der Text kann darüber hinaus als Leitlinie für den Forschungsrahmen des Instituts für Sozialforschung der ersten Jahre interpretiert werden (van Reijen/Schmid Noerr 1988: 172).

135 Der von Maurice Merleau-Ponty in den 195oer-Jahren aufgebrachte Begriff (MerleauPonty 1968 [1955]: 39-72) wurde in den 197oer-Jahren durch Perry Andersons Buch Über den westlichen Marxismus populär (Anderson 1978 [1976]). Anderson nennt Lukács, Korsch und Gramsci als »die wirklichen Begründer des ganzen Modells des westlichen Marxismus« (ebd.: 51). 
Die neue Verhältnisbestimmung zwischen Philosophie und Marxismus, wie sie an Lukács und Korsch beobachtet werden kann, ist - so die argumentative Stoßrichtung - für Horkheimer und Adorno eine entscheidendeVoraussetzung, damit sie ihr neues theoretisches Programm (die Kritische Theorie) als Philosophie präsentieren und positionieren können (etwa durch das gemeinsam verfasste Buch Dialektik der Aufklärung (1944), Adornos Minima Moralia (1951) oder dessen Negative Dialektik (1966)). Lukács' Aufsatzsammlung Geschichte und Klassenbewußtsein wird denn auch vielerorts als ein zwingender Einflussfaktor für die Entwicklung der Kritischen Theorie dargestellt. ${ }^{136}$ Vor allem Lukács (und weniger Korsch) bemüht sich explizit um eine philosophische Fundierung des Marxismus. Horkheimer und Adorno wiederum nehmen diese Fundierung auf und formulieren auf dieser Basis einen Erneuerungsanspruch der Philosophie insgesamt. Die Schwerpunktverlagerung des Marxismus »hin zur Philosophie« (Anderson 1978 [1976]: 77) ist für den Erneuerungsanspruch der Kritischen Theorie entscheidend. Diese Entwicklung kann nicht nur in ideeller, sondern auch in institutioneller Hinsicht beobachtet werden. »Der auffallendste Zug der gesamten Tradition [des westlichen Marxismus, MD] ist die überwältigende Dominanz von Berufsphilosophen. Gesellschaftlich gesehen bedeutete das eine immer stärkere Verankerung der in dieser Epoche produzierten Theorie im akademischen Bereich « (ebd.: 55$)$.

Im Folgenden wird an Lukács und Korsch in einem ersten Schritt deutlich gemacht, wie diese den Marxismus gewissermaßen re-philosophieren. Ihr zentrales Anliegen ist die Rückbindung der Philosophie an materielle Verhältnisse, um sie davon ausgehend als Ideologie der bürgerlich-kapitalistischen Gesellschaft zu entlarven. Philosophiekritik (Theorie), so folgt daraus, ist mit Gesellschaftskritik (Praxis) untrennbar verbunden. Lukács und Korsch aktualisieren damit das Marx'sche Theorem der Verwirklichung der Philosophie in der Praxis. Danach wird gezeigt, wie Adorno und Horkheimer vom Ausgangspunkt des Scheiterns dieses Theorems in der Praxis ihren philosophischen Erneuerungsanspruch formulieren. »Philosophie«, so die ersten Sätze aus Adornos Negativer Dialektik, »die einmal überholt schien, erhält sich am Leben, weil der Augenblick ihrer Verwirklichung versäumt ward. Das summarische Urteil, sie habe die Welt bloß interpretiert, sei durch Resignation vor der Realität verkrüppelt auch in sich, wird zum Defaitismus der Vernunft,

136 »Ohne seinen [Lukács', MD] inspirierenden Geist wäre auch die kritische Theorie nicht zu begreifen, die wir ohne `Geschichte und Klassenbewußtsein` gar nicht verstehen können« (Claussen 2015: 175). Auch Jay betont, »daß viel von dem, was die Paramarxisten geschrieben haben, ohne gewisse Schriften von Lukács in dieser Weise gar nicht denkbar wäre« (Jay 1981 [1973]: 210). 
nachdem die Veränderung der Welt misslang « (Adorno 1966: 15). Adorno und Horkheimer nehmen die von Lukács und Korsch konzeptualisierte gegenseitige Durchdringung von Gesellschaft und Philosophie insofern affirmativ auf, dass sie die Philosophie mit den zeitgenössischen Sozialwissenschaften verbinden, diese aber dezidiert von der als relativistisch verstandenen Wissenssoziologie abgrenzen. Auf dieser Basis wiederum formulieren sie ihren Erneuerungsanspruch: Die einzige noch legitime Aufgabe der Philosophie bestehe in der Kritik an der Gesellschaft.

\subsection{Die Philosophie als Problem der Gesellschaft (Lukács und Korsch)}

Sowohl Lukács' Aufsatzsammlung Geschichte und Klassenbewußtsein als auch Korschs Aufsatz Marxismus und Philosophie sind 1923 erschienen. Beide Schriften gelten - wie es Hanno Plass jüngst formulierte - als »Wendepunkt in der marxistischen Theorie nach dem Ersten Weltkrieg« (Plass 2015: 303-304). Obwohl Marxismus und Philosophie in den 1920er-Jahren ebenso bekannt gewesen sein soll wie Geschichte und Klassenbewußtsein (Claussen 2015: 175), nimmt letzteres Buch in der Rezeptionsgeschichte des Verhältnisses von Marxismus und Philosophie eine ungleich bedeutendere Rolle ein. Die beiden Schriften unterscheiden sich hinsichtlich ihres Umfangs, ihrer Themen und ihrer Fragestellungen. ${ }^{137}$ Dass die beiden Texte in der Fachliteratur kontinuierlich als Gründungsdokumente des westlichen Marxismus genannt werden, verweist jedoch darauf, dass sie sich trotz ihrer Unterschiede in einem zentralen Aspekt überschneiden. Er wurde bereits angesprochen: Sowohl in Lukács' als auch in Korschs Schriften wird der Marxismus in bestimmter Weise philosophisch unterlegt. Beide Autoren fordern den Einbezug der Philosophie in die zeitgenössische marxistische Theorie (vor allem Korsch) bzw. eine philosophische Fundierung des Marxismus (vor allem Lukács). Bezüglich Korsch schreibt etwa Erich Gerlach: »Indem Korsch nachweist, daß die >Verflachung< des Marxismus durch das Nichtverstehen seines philosophischen Gehalts >vermittelt ist und daß vom Standort des so veränderten Marxismus der wirkliche Zusammenhang von Theorie und Praxis unbegreifbar geworden ist, hat er zugleich begründet, daß zur >Wiederherstellung « des >unverfälschten< Marxismus auch die Klärung seines wirklichen Verhältnisses zur Philosophie erforderlich ist « (Gerlach 1966: 12). Und in Bezug auf Lukács schreibt Eberhard Braun: »Mit `Geschichte und Klassenbewusstsein« setzt die ausdrücklich

137 Der Eindruck von Fabian Kettner, wonach Korsch weniger als Lukács unter dem »Bann« der marxistischen Orthodoxie gestanden habe, wird hier geteilt (Kettner 2012: 379). 
philosophische Marx-Interpretation ein, die vor allem Marxens Verhältnis zur deutschen spekulativen Philosophie, insbesondere zu der Hegelschen, ins Zentrum ihres Interesses rückt. Lukács kommt das kaum zu überschätzende Verdienst zu, die Diskussion als erster auf das angemessene Niveau gehoben zu haben « (Braun 1992: 173). Kurz: Sowohl Lukács als auch Korsch wird das Verdienst zugeschrieben, den Marxismus philosophisch fundiert bzw. die marxistische Philosophie für das 20. Jahrhundert aktualisiert zu haben. ${ }^{138}$

Wenn im Folgenden einzelne Textstellen aus Geschichte und Klassenbewußtsein und Marxismus und Philosophie hinsichtlich der Frage interpretiert werden, wie Lukács und Korsch den Marxismus philosophisch unterlegen, um genau dadurch ein Instrument an der Hand zu haben, mit dem es möglich wird, die Philosophie als ein Produkt der bürgerlichen Gesellschaft zu kritisieren, ist es unvermeidlich, dass die betreffenden Aussagen zuweilen aus ihrem Gesamtzusammenhang gerissen werden. ${ }^{139}$ Gerechtfertigt ist dieses Vorgehen durch das Ziel, bestimmte Argumentationsstrategien herauszuarbeiten: Mit welchen Argumentationsstrategien konstituieren Korsch und Lukács die Philosophie als ein gesellschaftliches Problem? Und wie bestimmen sie damit zusammenhängend die Philosophiekritik als wichtigen Aspekt marxistischer Theorie? Eine zentrale Ausgangslage der Argumentation von Lukács und Korsch - so wird der folgende Abschnitt deutlich machen - liegt in der Annahme, dass die Methode von Marx unanfechtbar die richtige Methode ist.

\section{Ausgangslage: Materialistische Dialektik}

Korsch und Lukács monieren in ihren Schriften, dass Marx und Engels in der zeitgenössischen Literatur sowohl von marxistischer als auch von bürgerlicher Seite verkürzt, entstellt oder schlicht falsch rezipiert werden. Es gebe, sagt Korsch in seinem 1922 veröffentlichten Text Kernpunkte der materialistischen Geschichtsauffassung, »unter den Schriften über die materialistische Geschichtsauffassung, die in deutscher Sprache vorliegen, nur sehr wenige Werke, in

138 In der Sekundärliteratur gibt es unzählige Textstellen, die diesen Aspekt betonen. Die Forderung von Geschichte und Klassenbewußtsein bzw. Marxismus und Philosophie sei gewesen, so sagt etwa Detlev Claussen, »den philosophischen Kern aus der Marx'schen Theorie wieder hervor[zu]holen, denn dieser philosophische Kern [sei] der emanzipatorische « (Claussen 2015: 175). »Korsch war neben Lukács der bedeutendste jener Marxisten, die sich bemühten, die originale Philosophie - oder vielmehr AntiPhilosophie-Marxens [...] zu rekonstruieren und auf dieser Grundlage eine revolutionäre [...] Strategie des Klassenkampfes zu entwickeln« (Kolakowski 1979 [1978]: 337). Maurice Merleau-Ponty spricht bezüglich Lukács von einer "philosophischen Lektüre der Geschichte« (Merleau-Ponty 1978 [1976]: 55-57).

139 Es geht also um die Überschneidung beider Schriften und nicht um einen Vergleich oder um eine Auslegung der Texte. 
denen der Grundgedanke von Marx nicht entweder außerordentlich versimpelt oder aber förmlich entmannt worden ist « (Korsch 1922: 5). In politischer Hinsicht kritisieren Korsch und Lukács die Gründung und Verbreitung der Unabhängigen Sozialdemokratischen Partei Deutschlands (USPD). Sie wenden sich sowohl gegen die »Revisionisten « (um Eduard Bernstein) als auch gegen die »Zentristen « (um Karl Kautsky). Lukács schreibt in seinem Aufsatz »Was ist orthodoxer Marxismus?«:»[...] auch die Gegner Bernsteins, die Hüter der angeblichen Orthodoxie des Marxismus, Kautsky und die VulgärMarxisten, haben die dialektische Methode und mit ihr den revolutionären Schwung des Sozialismus verflacht« (Lukács 2013 [1923]: 63). Korsch untermauert dieselbe Kritik mit einem Gleichnis: »So entsteht denn auch hier, wie in so vielen anderen philosophischen Debatten, das betrübliche Schauspiel, dass >der eine den Bock melkt, und der andere ein Sieb darunter hält< (Kant) « (Korsch 1922: 5). ${ }^{140}$ Sowohl die Auslegungen der »zentristischen Bockmelker« (Kautsky) als auch jene der »reformistischen Siebunterhalter« (Bernstein) würden darauf hinauslaufen, die Grundgedanken von Marx zu verfälschen (ebd.). ${ }^{141}$ Lukács und Korsch kritisieren darüber hinaus die Bestrebungen, das Prinzip der materialistischen Dialektik in eine »ökonomistische« oder »darwinistisch-biologistische Metaphysik« (ebd.) umzuwandeln. Die Notwendigkeit einer philosophischen Unterlegung des Marxismus wird also mit der Kritik an den in je unterschiedlichen Varianten praktizierten Verwissenschaftlichungen des Marxismus dieser Zeit begründet.

Einig sind sich Lukács und Korsch nicht nur über die Verflachung der materialistischen Dialektik in der zeitgenössischen Literatur, sondern auch darin, wie dieser Verflachung zu begegnen sei, nämlich durch eine Rückbesinnung auf die Methoden von Marx und Engels selbst: »Bei diesem Stand der Dinge«, schreibt Korsch, »bleibt der einzige Weg, wie man sich des wirklichen Sinnes des Marxschen >Materialismus< bemächtigen kann, eine Vertiefung in die Art und Weise, wie Marx und Engels ihr materialistisches

140 Dieses auf die Antike zurückgehende Bild verdeutlicht die lächerliche Szene, wie auf eine sinnlose Ausgangsfrage (einen Bock melken) eine sinnlose Antwort folgt (mit einem Sieb die Milch auffangen). Kant nimmt dieses Gleichnis in der Kritik der reinen Vernunft in Bezug auf die Frage >Was ist Wahrheit? $<$ auf.

141 Die Veröffentlichung von Marxismus und Philosophie fiel in eine Zeit, in der Korsch politisch äußerst aktiv gewesen ist. Dies widerspiegelt sich u.a. in den Auseinandersetzungen mit Karl Kautsky. Beide haben die politische Absicht des jeweils anderen scharf kritisiert (u.a. Kautsky 1924; Korsch 1971 [1929]). 
Prinzip in ihren Werken selber angewendet haben « (ebd.). ${ }^{142}$ Es müsse um die Anwendung des materialistischen Prinzips gehen, behauptet Korsch. In seinem Aufsatz Marxismus und Philosophie wendet er denn auch »das materialistischdialektische Prinzip Marxens auf die gesamte Geschichte des Marxismus « an (Korsch: 1966 [1923]: 97).143 Auch für Lukács gilt es, »das Wesen der Methode von Marx richtig zu verstehen und richtig anzuwenden, keineswegs aber sie in irgendeinem Sinne zu >verbessern « (Lukács 2013 [1923]:164). Auf die zu dieser Zeit breit diskutierte Frage, worin die Orthodoxie des Marxismus eigentlich bestehe, gibt Lukács folgende Antwort:

Orthodoxer Marxismus bedeutet also nicht ein kritikloses Anerkennen der Resultate von Marx' Forschung, bedeutet nicht einen »Glauben« an diese oder jene These, nicht die Auslegung eines »heiligen« Buches. Orthodoxie in Fragen des Marxismus bezieht sich vielmehr ausschließlich auf die Methode. Sie ist die wissenschaftliche Überzeugung, daß im dialektischen Marxismus die richtige Forschungsmethode gefunden wurde, daß diese Methode nur im Sinne ihrer Begründer ausgebaut, weitergeführt und vertieft werden kann. Daß aber alle Versuche, sie zu überwinden oder zu »verbessern « nur zur Verflachung, zur Trivialität, zum Eklektizismus geführt haben und dazu führen mußten. (ebd.: 171)

Lukács bezieht seine Rückbesinnung auf Marx also lediglich auf dessen Methode. Ágnes Heller, einst Assistentin von Lukács, fasst diesen Aspekt pointiert zusammen: »Die >dialektische< Methode [...], das ist die Totalität, das Ganze, das Wahre« (Heller 2015: 14). Wie im nächsten Abschnitt deutlich wird, eröffnet Lukács' und Korschs Argumentationsstrategie, aus Marx' Theoriegebäude lediglich dessen materialistisch-dialektische Methode gelten zu lassen, weitreichende und neue Perspektiven auf die Philosophie selbst. Die in den Kapiteln zu Husserl und zum Wiener Kreis herausgearbeitete Strategie, philosophische Erneuerung durch philosophische Methoden zu legitimieren, begegnet hier erneut: Durch ihre Anwendung der materialistischen Dialektik auf den Marxismus (Korsch) und die Philosophie (Lukács) wird gleichzeitig die marxistische Philosophie aktualisiert. ${ }^{144}$

142 In seinem Text Kernpunkte der materialistischen Geschichtsauffassung >materialisiert< Korsch diesen Anspruch gewissermaßen, indem er nach einem 18-seitigen Einleitungsteil lediglich Originalzitate hauptsächlich von Marx und Engels auflistet.

143 Mit seinem Vorgehen sucht Korsch Antworten auf die >Krise des Marxismus«. Korsch und auch Lukács fassen diese Krise - sie drückt sich für sie vor allem im Scheitern der Zweiten Internationale aus - somit als ein Produkt historischer Entwicklungen auf.

144 Die Analogie zu den anderen beiden Kapiteln ist augenscheinlich: Offensichtlich ist die Entwicklung und/oder Vertiefung bestimmter Methoden ein für philosophische Erneuerungspraktiken wesentliches Element: Wo Husserl auf die Phänomenologie und 


\section{Argumentativer Rückgriff auf die Soziologie}

Weder Lukács noch Korsch streben - selbstredend - eine Interpretation oder Erweiterung des marxistischen Theoriegebäudes an, so wie sie es den »zentristischen « wie »reformistischen « »Marx-Apologeten « unterstellen, sondern sie unterziehen den Marxismus (vor allem Korsch) und die Philosophie (vor allem Lukács) einer materialistisch-dialektischen Analyse.

Lukács' Analysen über die >Antinomien des bürgerlichen Denkens` im Aufsatz »Die Verdinglichung und das Bewusstsein des Proletariats « gehören mutmaßlich zu seinen für die Philosophie einflussreichsten Textstellen. Er tritt hier mit dem Vorhaben auf, die Widersprüche der modernen idealistischen Philosophie aus den gesellschaftlichen Verhältnissen heraus zu erklären, indem er die materialistische Dialektik auf die Philosophie selbst anwendet. Die Widersprüche der idealistischen Philosophie, so Lukács, seien keineswegs der »Unfähigkeit der Philosophen« geschuldet, sondern sie seien »die logischmethodologische Formulierung des modernen Gesellschaftszustandes« (Lukács 2013 [1923]: 307).

Lukács beginnt seine Analyse der modernen idealistischen Philosophie mit der »Kopernikanischen Wendung « (ebd.: 287). Mit diesem Ausdruck habe Immanuel Kant klar ausgesprochen, dass die moderne Philosophie die Welt nicht mehr »als ein unabhängig vom erkennenden Subjekt entstandenes (z.B. von Gott geschaffenes) Etwas « hinnehme, sondern »sie vielmehr als eigenes Produkt « begreife (ebd.: 287-288). Die ganze moderne Philosophie von Descartes über Hobbes, Spinoza und Leibniz habe sich dieses Problem gestellt, dass »der Gegenstand der Erkenntnis deshalb und insofern von uns erkannt werden kann, weil und inwiefern er von uns selbst erzeugt worden ist « (ebd.: 288). Dieses Motiv, das die gesamte idealistische Philosophie durchziehe, hat jedoch gemäß Lukács einen blinden Fleck: Es setzt die formell-mathematische, rationale Erkenntnis mit Erkenntnis überhaupt gleich. »Die Frage, warum und mit welchem Rechte der menschliche Verstand gerade solche Systeme der Formen als sein eigenes Wesen (im Gegensatz zum >gegebenen<, fremden, unerkennbaren Charakter der Inhalte dieser Formen) auffasst, taucht nicht auf « (ebd.).

Lukács bezeichnet diese Gleichsetzung von rationaler Erkenntnis mit Erkenntnis überhaupt als naiv und dogmatisch. »Und wenn wir die Frage so stellen, so erscheint die (selbst bei den >kritischsten< Philosophen) naive und dogmatische Gleichstellung von formell-mathematischer, rationaler Erkenntnis

der Wiener Kreis auf die Logik als die einzig richtige Methode für die Philosophie >pocht<, pochen Lukács und Korsch (und in veränderter Form auch Horkheimer und Adorno) auf die Dialektik als richtige philosophische Methode. 
einerseits mit Erkenntnis überhaupt, andererseits mit >unserer Erkenntnis als das charakteristischste Kennzeichen dieser ganzen Epoche« (ebd.: 289). Die gesamte moderne Philosophie erkenne nicht, dass es Rationalismus zwar in jeder historischen Epoche gebe, esjedoch darauf ankäme, »auf welches Material dieser Rationalismus bezogen wird und welche Rolle ihm im Gesamtsystem der menschlichen Erkenntnisse und Zielsetzungen zugemutet wird« (ebd.: 29o, Herv.i.O). Bisher sei jeder Rationalismus stets nur ein »Teilsystem « gewesen. Heute jedoch trete er von den Philosophen unbemerkt als das herrschende Erkenntnisprinzip auf. »Das Neue im modernen Rationalismus bestehe darin, daß er - im Laufe der Entwicklung in steigendem Maße - mit dem Anspruch auftritt, das Prinzip des Zusammenhanges sämtlicher Phänomene, die sich dem Leben des Menschen in Natur und Gesellschaft gegenüberstellen, entdeckt zu haben « (ebd.). Kurz: Die klassische Philosophie habe den Rationalismus »zu einem überhistorischen Prinzip im Wesen des menschlichen Denkens« gemacht. ${ }^{145}$ Ein Schlüsselbegriff in Lukács' Kritik an der Philosophie - so wird deutlich - ist der Begriff der Rationalisierung.

Dass Lukács seine zentralen Thesen in seinem Verdinglichungsaufsatz im Rückgriff auf die Soziologie Max Webers vorbringt, ist in unzähligen Publikationen dargestellt (z.B. Fetscher 1973; Beiersdörfer 1986; Fechner 2012). An dieser Stelle kommt es lediglich darauf an, hervorzuheben, dass Webers Theoreme für Lukács Argumente konstitutiv sind. Lukács nutzt Webers Rationalisierungstheorie nicht lediglich als Untermauerung seiner Thesen, sondern sie ist ein konstitutives theoretisches Element für seine eigene Theorie. Philosophische, marxistische und soziologische Perspektiven werden von ihm inhärent miteinander verknüpft. Er nimmt also zeitgenössische soziologische Wissensperspektiven konstruktiv auf, um marxistische Denkformen zu aktualisieren. Kurt Beiersdörfer, der in den 198oer-Jahren die Beziehung zwischen Lukács und Weber untersucht hat, untermauert diesen Aspekt, wenn er schreibt: »Indem Lukács die positiven Resultate von Webers soziologischer Marx-Kritik zu integrieren versucht, entwickelt er eine gesellschaftstheoretische Auffassung, die - trotz aller ostentativ vorgetragenen Marx-Orthodoxie - eine qualitativ neue Variante des Marxismus darstellt« (Beiersdörfer 1986: 166). Erst mit dem Rückgriff auf philosophieexterne Theoreme gelingt es Lukács, theoretisch-methodische Instrumentarien zu entwickeln, mit denen der Marxismus philosophisch aktualisiert werden

145 Am klarsten trete diese Problematik in der Bedeutung, die der Begriff des $>$ Dinges an sich bei Kant habe, zutage (Lukács 2013 [1923]: 291). 
kann. ${ }^{146}$ Das Konzept der Gesellschaft nimmt innerhalb dieser Aktualisierung eine Schlüsselrolle ein.

\section{Das Problem: Verdinglichte Gesellschaft als Totalität ${ }^{147}$}

»Die Kategorie der Totalität, die allseitige, bestimmende Herrschaft des Ganzen über die Teile ist das Wesen der Methode, die Marx von Hegel übernommen und originell zur Grundlage einer ganz neuen Wissenschaft umgestaltet hat« (Lukács 2013 [1923]: 199). ${ }^{148}$ Die Totalität ist für Lukács die Gesellschaft. »Die dialektische Methode bei Marx geht auf die Erkenntnis der Gesellschaft als Totalität aus « (ebd.: 199-200). Die Gesellschaft erscheint bei Lukács als eine übergeordnete Einheit, als eine Kategorie, die - in ihren Gesamtzusammenhängen - potenziell analysiert werden kann. Diese Einheit wiederum ist gemäß Lukács verdinglicht, d.h., sie wird von der bürgerlichkapitalistischen Warenstruktur hervorgebracht und bestimmt. Kapitalistische Gesellschaftsstrukturen durchdringen nicht nur die ökonomischen Verhältnisse, in denen Menschen leben, sondern zugleich alle Formen von Subjektivität und theoretischer Wissensproduktion. »Lukács versuchte so [durch die Thematisierung der Warenanalyse und der in ihr formulierten Einheit von Gesellschafts- und Erkenntniskritik, MD] die scheinbar voneinander getrennten subjektiven und objektiven Momente der kapitalen Vergesellschaftung als unterschiedliche Ausdrücke der kapitalistischen Totalität zu kritisieren « (Fechner 2012: 225). Mit anderen Worten, das Bewusstsein der Menschen ist ebenso verdinglicht wie die gesellschaftlichen Warenverhältnisse. Im Unterschied zu den anderen beiden Fallbeispielen vorliegender Arbeit wird hier die Vorstellung eines >reinen<, von anderen Faktoren unabhängigen Bewusstseins verabschiedet. Die Philosophie wird als Ausdruck

146 Wie weiter unten deutlich werden wird, setzen sich Horkheimer und Adorno im Unterschied zu Lukács weniger inhaltlich mit zeitgenössischen soziologischen Konzepten auseinander, als dass sie die Soziologie in generalisierender Weise als eine produktive Wissenschaft verstehen, mit der es sich zu verbinden gilt.

147 Die Zitate in diesem Abschnitt stammen entweder aus Lukács' Aufsatz »Rosa Luxemburg als Marxist« oder aus »Die Verdinglichung und das Bewußtsein des Proletariats«, seinem wohl berühmtesten Aufsatz aus Geschichte und Klassenbewußtsein.

148 Es wird vielerorts betont, dass es ein Verdienst von Geschichte und Klassenbewußtsein gewesen sei, den (Hegel'schen) Begriff der Totalität wieder in die Diskussionen eines kritischen Marxismus eingeführt zu haben (z.B. Müller/Rhein 2005: 219). Auch Lukács selbst betont diesen Aspekt 1967 in seinem Vorwort zur Neuauflage seines Buches: »Es ist sicher ein großes Verdienst von >Geschichte und Klassenbewußtsein<, dass es der Kategorie der Totalität, die die >Wissenschaftlichkeit $<$ des sozialdemokratischen Opportunismus ganz in Vergessenheit drängte, wieder jene methodologische Zentralstelle zuwies, die sie in den Werken von Marx immer hatte« (Lukács 1967: 22). 
einer tiefer liegenden Struktur verstanden. »Aus der verdinglichten Struktur des Bewusstseins ist die moderne kritische Philosophie entstanden « (Lukács 2013 [1923]: 287). Es wird klar, worin Lukács' zentrale Argumentationsstrategie besteht: Er argumentiert für die Annahme einer Struktur, die grundlegender ist als die Philosophie. Diese Struktur ist die kapitalistische Warenstruktur bzw. die gesellschaftliche Struktur. Umgekehrt versteht er die Philosophie nach Marx' Theorem, wonach das Sein das Bewusstsein bestimme und nicht umgekehrt - als Ausdruck der gesellschaftlichen Totalität.

Die Konsequenzen, die Lukács aus dieser Einsicht zieht, ergeben eine scheinbar ausweglose Situation, die an Seidels verhängnisvollen Zirkel erinnert: Die durchrationalisierten, auf kapitalistische Nutzenmaximierung ausgerichteten gesellschaftlichen Verhältnisse erscheinen den einzelnen Menschen als eine Art »zweiter Natur « ${ }^{149}$ Lukács verbindet hier Hegels Überlegungen zum Verhältnis zwischen Natur und Geist mit Marx' Überlegungen zu einer Kritik an der politischen Ökonomie, d.h., er verwendet den Begriff der »zweiten Natur« im Zusammenhang mit seiner Kritik an einer entfremdeten und verdinglichten Welt. Der Ablauf der »selbsterschaffenen, >selbsterzeugten< Wirklichkeit« trete den Menschen »mit derselben unerbittlichen Gesetzmäßigkeit« entgegen, »wie es früher die irrationellen Naturmächte (pünktlicher: die in dieser Form erscheinenden gesellschaftlichen Verhältnisse) getan haben « (ebd.: 307). Menschen seien also gleichsam in ihrer »zweiten Natur« gefangen, gesellschaftlichen Abläufen scheinbar machtlos ausgeliefert. ${ }^{150}$ So wie die Philosophie nur ein Ausdruck gesellschaftlicher Verhältnisse ist, ist es auch der einzelne Mensch bzw. sein Bewusstsein. Wie, so fragt sich dann aber, lässt sich der verhängnisvollen kapitalistischen Gesellschaftsentwicklung entgehen, wenn die einzelnen Menschen diesen Vorgängen blind ausgeliefert sind? Wie >löst` Lukács das für Seidel unausweichlich scheinende Problem, nämlich

149 Der Ausdruck der »zweiten Natur« hat als Folge des Buches Mind and World von John McDowell (1994) ein Revival erfahren. »Die daran anschließende Diskussion hat zudem dazu beigetragen, das Interesse in Richtung einer Aktualisierung der Hegelschen Konzeption zu lenken« (Ranchio 2016: 27).

150 Stefan Müller und Johannes Rhein fassen die Situation etwa wie folgt zusammen: Die gesellschaftliche Totalität, die doch nur historisches Produkt der Menschen sein kann, steht den zum bloßen Anhängsel degradierten Menschen, die als Vereinzelte über dieses ihr Produkt keine Verfügung haben, als »zweite Natur« gegenüber. In dieser Verkehrung produziert jenes Produkt sogar alle Formen von Subjektivität, in der die Menschen zu leben und jene Verhältnisse zu reproduzieren gezwungen sind. Gesellschaft als Totalität heißt auch: Kein einziges ihrer Momente kann unmittelbar herausgelöst und zum erkenntnisleitenden oder gar emanzipatorischen Prinzip erklärt werden. Sie bleiben stets verdinglichte, isolierte Momente, die unmöglich das ihnen gegenüber verselbständigte Ganze ergreifen können (Müller/Rhein 2005: 219-220). 
dass der menschliche Geist durchgängig von gesellschaftlichen Strukturen bestimmt ist?

Anders, als es möglicherweise zu erwarten wäre, ist es für Lukács keineswegs die Philosophie, der das Vermögen zukommt, dem verhängnisvollen Zirkel gesellschaftlicher Totalität zu entgehen. Im Gegenteil: »Die kapitalistische Trennung des Produzenten vom Gesamtprozeß der Produktion, die Zerstückelung des Arbeitsprozesses in Teile, die die menschliche Eigenart des Arbeiters unberücksichtigt lassen, die Atomisierung der Gesellschaft in planlos und zusammenhanglos drauflosproduzierende Individuen usw. mußte auch das Denken, die Wissenschaft und Philosophie des Kapitalismus tiefgehend beeinflussen« (ebd.: 307). Der Philosophie, als ein Zweig der bürgerlichen Wissenschaft, sei es strukturell verwehrt, die gesellschaftliche Totalität erfassen zu können. Im Zuge der Herausbildung der bürgerlich-kapitalistischen Gesellschaft habe sie sich zwar insofern spezialisiert, dass sie »die Einzelheiten ihres gesellschaftlichen Daseins im steigenden Maße beherrscht«, gleichzeitig aber habe sie »die Möglichkeit zur gedanklichen Bewältigung der Gesellschaft als Totalität und damit die Berufung zu ihrer Führung [...] « verloren (ebd.: 299). Kurz: In der kapitalistischen Gesellschaft habe die bürgerliche Philosophie den Blick auf das »Ganze« und damit ihre Berufung - die »Führung« - verloren.

\section{Die Lösung: Klassenrevolution}

»Lukács' politisches Denken während der Weimarer Republik«, schreibt Michael Festl, »besteht aus zwei Teilen: einer soziologischen Analyse der Verdinglichung und einer philosophischen Entschlüsselung des geschichtlichen Geschehens [...] « (Festl 2019: 62). Beide Teile dürften, so Festl, keinesfalls als voneinander getrennt betrachtet werden. Die beiden Teile - soziologische Analyse und geschichtsphilosophische Prämissen - kulminieren gewissermaßen im Ausweg, den Lukács aus der verhängnisvollen Situation gesellschaftlicher Verdinglichung vorschlägt: im Aufstand der Arbeiterklasse. Diese Lösung ist gleichzeitig der - auch von Lukács selbst ${ }^{151}$ - am vehementesten kritisierte Aspekt seiner Theorie. »Ist die endgültige Wirtschaftskrise des Kapitalismus eingetreten, so hängt das Schicksal der Revolution (und damit der Menschheit) von der ideologischen Reife des Proletariats, von seinem Klassenbewußtsein

$15^{1}$ Im Vorwort zur Neuauflage von Geschichte und Klassenbewußtsein (1967) nimmt Lukács diese »letzte philosophische Grundlage« eines im »Geschichtsprozess sich realisierenden identischen Subjekt-Objekt[s] « zurück (Lukács 1967: 24-25). In Bezug auf die Wirkungsgeschichte seines Buches sagt er: »Leider weiß ich, daß aus Gründen der gesellschaftlichen Entwicklung und der von ihr produzierten theoretischen Einstellungen, das, was ich heute als theoretisch falsch ansehe, oft zu den wirksamsten und einflussreichsten Momenten der Wirkung gehört« (ebd.: 29). 
ab« (Lukács 2013 [1923]: 245). Das Bewusstsein der Arbeiterklasse über ihre gesellschaftliche Lage sei also die Bedingung sowohl für eine gesellschaftliche Revolution als auch für eine Veränderung der Philosophie. Bei Lukács ist, wie Willem van Reijen schreibt, das gesellschaftliche Bewusstsein des Proletariats mit der materialistischen Theorie der Gesellschaft tendenziell identisch. »Idealistisch überhöht bedeutet das, daß die Identität von Klassenbewusstsein und Theorie die notwendige und hinreichende Bedingung ist für die Änderung der gesellschaftlichen Ordnung « (van Reijen 1984: 30). In Bezugnahme auf Hegel konzipiert Lukács eine Theorie, in der das Proletariat ein Klassenbewusstsein entwickelt und so eine Stufe des historischen Prozesses das Identisch-Werden von Subjekt und Objekt - verwirklicht. ${ }^{152}$

Die Philosophie nimmt innerhalb dieser geschichtsteleologischen Konzeption eine doppelseitige Rolle ein: Auf der einen Seite bedeutet die Engführung von Philosophie und Klassenrevolution, die Philosophie als einen Bereich vorzustellen, an und in dem gesellschaftliche Veränderung stattfindet. ${ }^{153}$ Ideologien und insbesondere die Philosophie werden nicht lediglich als ein Reflex sozialer Verhältnisse vorgestellt, sondern als »konstitutive[] Momente der menschlichen Welt « (Vranicki 1974 [1961/1971]: 515). ${ }^{154}$ Gerade weil die Philosophie (bzw. Theorie) beides ist, sowohl Produzentin als auch Produkt gesellschaftlicher Prozesse, wird sie als eine Praxis begriffen. Die Philosophie bilde also keine sewigen Korsch die bürgerliche Philosophie suggeriere -, sondern vielmehr sei sie ein aktives und konstituierendes Element gesellschaftlicher Verhältnisse. Auf der anderen Seite wird die Philosophie als ein Hemmnis für die Klassenrevolution dargestellt: Als ideologischer Überbau der bürgerlichen Ordnung erschwert oder verhindert sie sogar die Entwicklung des proletarischen Bewusstseins.

Besonders deutlich wird dieser Aspekt in einer Textpassage aus Korschs Text Kernpunkte der materialistischen Geschichtsauffassung: Die bürgerliche Philosophie sei von der Vorstellung »besessen «, dass es »irgendwelche >ewigen<, unvergänglichen und unwandelbare Wahrheiten >an sich< [gäbe], nach denen

$15^{2}$ Wie weiter unten deutlich wird, ist die Kritik an jeglichem Totalitätsdenken eine zentrale Argumentationspraktik der Kritischen Theorie.

153 »Der Klassenkampf kann sich also nicht auf die ökonomische und politische Aktion beschränken, sondern muss als notwendigen Bestandteil des revolutionären Gesamtprozesses auch die >geistige Aktion< umfassen, die Korsch als revolutionäre wissenschaftliche Kritik und agitatorische Arbeit versteht « (Buckmiller 1973: 47).

154 Wie Predrag Vranicki betont, liegt in diesem Aspekt eine Gemeinsamkeit von Korsch und Lukács. Sie kritisieren die in der Periode der Zweiten Internationale sehr verbreiteten »vulgär-marxistischen Konzeptionen, nach denen die Ideologie und insbesondere die Philosophie nur ein Reflex der sozialen Verhältnisse, ja Schein oder gar bloße gedankliche, gegenstandslose Spekulation seien (Vranicki 1974 [1961/1971]: 515). 
die Wissenschaft und die Philosophie zu suchen hätten, bis sie sie endlich fänden und nun in hinfort nicht mehr veränderlicher Weise besäßen« (Korsch 1922: 20). Eine solche Vorstellung sei »ein Traum, und nicht einmal ein schöner, denn eine unwandelbare, unveränderliche Idee wäre natürlich zugleich eine nicht mehr entwicklungsfähige Idee« (ebd.). Für dergleichen könne sich »natürlich nur eine saturierte Klasse begeistern, die sich in dem gegenwärtigen Zustande wohl und bestätigt fühlt« (ebd.). Niemals aber tauge es »für eine vorwärtstreibende und drängend, in dem gegenwärtig erreichten Zustand also notwendig unbefriedigte Klasse« (ebd.). Nur verwöhnte Wohlstandsbürger, so Korsch, seien daran interessiert, die Idee ewiger Wahrheiten aufrechtzuerhalten. Ohne gesellschaftlichen Umbruch, so die Implikation, könne sich die Philosophie ihrer »Besessenheit « von dieser Idee nicht bewusst werden. Kritik an der (bürgerlichen) Philosophie lässt sich also lediglich ausgehend vom Standpunkt der Arbeiterklasse üben. Dafür wiederum sei eine Veränderung der materiellen Bedingungen in Form einer Revolution zwingend: »Diese gesellschaftlichen Bewußtseinsformen können vielmehr auch im Denken, auch im Bewußtsein nur aufgehoben werden unter gleichzeitiger praktisch-gegenständlicher Umwälzung der in diesen Formen bisher begriffenen materiellen Produktionsverhältnisse selbst « (Korsch 1966 [1923]: 132). In der gesellschaftlichen Revolution besteht gleichzeitig die Möglichkeit einer Veränderung der Philosophie. Das heißt, dem >Verhängnis des Bewusstseins< lässt sich in Lukács' und Korschs Perspektive im Gegensatz zu Seidels Perspektivlosigkeit durchaus entgehen: durch die Veränderung der Gesellschaft. Mit Argumenten aus der marxistischen Tradition, so folgt daraus, formulieren Lukács und Korsch Möglichkeiten, wie der in Seidels Darstellung verhängnisvollen Soziologisierung des Geistes philosophisch zu entkommen ist. Die Lösung, die aus Lukács' und Korschs Überlegungen folgt, kulminiert in der gesellschaftlichen Revolution und damit zusammenhängend in der Figur der Aufhebung der Philosophie.

\section{Aufhebung der Philosophie: Durchdringung von Theorie und Praxis}

In seiner historischen Analyse des Marxismus stellt Korsch fest, dass in der Folge von Marx und Engels - also in der zweiten Hälfte des 19. Jahrhunderts - sowohl die bürgerliche als auch die marxistische Wissenschaft eine Abkoppelung des Marxismus von der Philosophie betrieben habe: »Die bürgerlichen Philosophieprofessoren versicherten sich gegenseitig, daß der Marxismus einen eigenen philosophischen Gehalt nicht besäße - und glaubten damit etwas Großes gegen ihn gesagt zu haben. Die orthodoxen Marxisten ihrerseits versicherten sich ebenfalls gegenseitig, daß ihr Marxismus seinem Wesen nach mit der Philosophie nichts zu tun habe - und glaubten damit etwas Großes für 
ihn zu sagen« (ebd.: 76). Diese Entkoppelung von Marxismus und Philosophie ist in Korschs Perspektive falsch. ${ }^{155}$ Falsch wäre es aber auch, an die Stelle der alten Philosophie schlicht eine neue - marxistische - setzen zu wollen. Marx und Engels, so Korsch mit seinem üblichen Rückbezug auf die >Gründerväter des Marxismus, seien »weit davon entfernt gewesen [...], eine neue Philosophie aufstellen zu wollen« (ebd.: 89). In Kernpunkte der materialistischen Geschichtsauffassung schreibt er: »Ganz falsch sind alle jene Vorstellungen der bürgerlichen und halbsozialistischen Gelehrsamkeit, die davon ausgehen, dass der Marxismus an die Stelle der bisherigen (bürgerlichen) Philosophie eine neue $>$ Philosophie< [...] setzen wollte. Karl Marx setzt sich stattdessen als Ziel die $>$ Kritikく der bürgerlichen Philosophie [...] (Korsch 1922: 8). Die Schwierigkeit, die aus diesem gleichsam negativen Verhältnis resultiert, beschreibt Korsch wie folgt:

Die eigentümliche und das richtige Verständnis des Problems Marxismus und Philosophie außerordentlich erschwerende Situation besteht nun aber darin, daß es so scheint, als ob gerade durch dieses Überschreiten der Grenzen des bürgerlichen Standpunktes, durch welches der wesentlich neue Inhalt der Philosophie des Marxismus grundsätzlich überhaupt erst ein begreiflicher Gegenstand wird, dieser Gegenstand als ein philosophischer zugleich aufgehoben und vernichtet würde. (Korsch 1966 [1923]: 89)

Aus der Überschreitung des bürgerlichen Standpunkts folge also zwingend die Auflösung und Vernichtung der Philosophie - auch derjenigen des Marxismus. Diese Gedankenfigur, so argumentiert Korsch weiter, sei ein Kernpunkt von Marx' und Engels Schriften und - entgegen der Ansicht vieler zeitgenössischer Interpreten - ernst zu nehmen. »Wir müssen [...] unbedingt davon ausgehen, daß nach den unmißverständlichen eigenen Worten von Marx und Engels nicht nur die Aufhebung der bürgerlichen Idealphilosophie, sondern damit zugleich auch die Aufhebung der Philosophie, d.h. aller Philosophie, als eine notwendige Konsequenz ihres neuen materialistisch-dialektischen Standpunkts erscheint« (ebd.: 91).

Völlig verkehrt wäre es nun aber gemäß Korsch, sich diese Aufhebung als eine Ersetzung der Philosophie durch die positiven Wissenschaften vorzustellen: Man bewundere »den Scharfsinn derjenigen neueren Marxisten, die [...] sich unter der Marx-Engelsschen Aufhebung der Philosophie eine Ersetzung dieser Philosophie durch ein System abstrakter und undialektischer positiver

155 Die Ursache dieser laut Korsch »oberflächlichen und unvollständigen Erfassung des [...] Sachverhalts« liege darin, dass in der zweiten Hälfte des 19. Jahrhunderts »jene >dialektische< Betrachtung des Verhältnisses von Philosophie und Wirklichkeit, Theorie und Praxis gänzlich verlorengegangen sei« (Korsch 1966 [1923]: 77-78). 
Wissenschaften vorgestellt haben« (ebd.: 109). Vermutlich zielt Korsch mit dieser Aussage auf Autoren und Autorinnen, die später u.a. als Wiener Kreis bzw. Berliner Gruppe bekannt werden sollten. Mit der Aufhebung der Philosophie meint er also etwas gänzlich anderes, als dass die Philosophie in naturwissenschaftliche oder ökonomische Modelle aufgehoben werden müsse, wie er es positivistischen Ansätzen unterstellt.. ${ }^{156}$ Er denkt ausgehend von der Praxis: Da die Philosophie und die Wissenschaften der Ausdruck der materiellen Verhältnisse sind, lösen sie sich zwingend auf, wenn sich die gesellschaftlichen Verhältnisse verändern:

Der wirkliche Gegensatz zwischen dem wissenschaftlichen Sozialismus Marxens und allen bürgerlichen Philosophien und Wissenschaften beruht vielmehr allein darauf, daß dieser wissenschaftliche Sozialismus der theoretische Ausdruck eines revolutionären Prozesses ist, der mit der völligen Aufhebung dieser bürgerlichen Philosophen und Wissenschaften, zugleich mit der Aufhebung derjenigen materiellen Verhältnisse, die in diesen Philosophien und Wissenschaften ihren ideologischen Ausdruck gefunden hatten, endigen wird. (Korsch 1923: 109)

Korsch wendet sich also vehement gegen die Vorstellung, wonach im Marxismus eine neue Philosophie enthalten sei. Im Gegenteil verteidigt und aktualisiert er die marxistisch-philosophische Gedankenfigur der Aufhebung der Philosophie durch die Praxis. Dem von Seidel konstatierten >Verhängnis des Bewusstseins< lasse sich - so die Implikation - entkommen, weil sich Praxis und Theorie gegenseitig durchdrängen. Die Praxis berge das Potenzial, Philosophie verändern zu können. Durch die Hintertüre der Praxis unterminieren Lukács und Korsch also gewissermaßen die für die Philosophie potenzielle Bedrohung, nämlich dass der menschliche Geist lediglich ein Ausdruck gesellschaftlicher Strukturen sei. Durch und in der Praxis lässt sich das Bewusstsein verändern. Der Philosophie wird dadurch ex negativo Handlungsfähigkeit zugesprochen.

Lukács und Korsch verstehen und analysieren die Philosophie, so kann zusammenfassend festgehalten werden, ausgehend von den materiellgesellschaftlichen Verhältnissen. Philosophie und Gesellschaft durchdringen einander wechselseitig, wobei der Praxis (Gesellschaft) ein klarer Vorrang vor

${ }_{156}$ Korschs Kritik zielt somit implizit auf die Idee der »Einheitswissenschaft«, die im Kapitel zum Wiener Kreis thematisiert worden ist. Auch hier spielte die Figur der Auflösung der Philosophie eine Rolle: Vor allem Otto Neurath sei Zeit seines Lebens von der Auflösung der Philosophie als einer autonomen Disziplin in ein umfassendes empiristisches Konzept des Enzyklopädismus überzeugt gewesen (Stadler 1997: 584). Gegen diese Weise der Auflösung der Philosophie schreibt Korsch an. 
der Theorie (Philosophie) eingeräumt wird. Diese zentrale Gedankenfigur wird von Adorno und Horkheimer - so soll im Folgenden gezeigt werden - aufgenommen und neu arrangiert: Die Erfahrung, dass die reale Verwirklichung der Philosophie in der Praxis gescheitert ist, ist für Horkheimer und Adorno die Basis, von der ausgehend sie das Verhältnis zwischen Theorie und Praxis, wie es von Lukács und Korsch gedacht wird, argumentativ letztlich umkehren. Wo die Philosophie in Lukács' und Korschs Perspektive ein Problem der bürgerlich-kapitalistischen Gesellschaft ist, wird die bürgerlich-kapitalistische Gesellschaft in Adornos und Horkheimers Perspektive zum Problem für die Philosophie.

\subsection{Die Gesellschaft als Problem der Philosophie (Adorno und Horkheimer)}

Horkheimer und Adorno gelten nebst Herbert Marcuse als Begründer der Kritischen Theorie. ${ }^{157}$ Mit ihnen wird im Folgenden ähnlich verfahren wie mit Lukács und Korsch: Die Unterschiede beider Autoren werden zwar an einzelnen Stellen angesprochen, sie stehen aber nicht im Zentrum der Analysen. Fokussiert werden vielmehr ihnen gemeinsame Argumentationsstrategien. Als Textgrundlagen ausgewählt wurden Texte, in denen Horkheimer und Adorno ihr philosophisches Programm explizit präsentieren: Horkheimers Antrittsrede als neuer Direktor des Instituts für Sozialforschung, die er 1931 unter dem Titel »Die gegenwärtige Lage der Sozialphilosophie und die Aufgaben des Instituts für Sozialforschung « an der Universität Frankfurt am Main gehalten hat, Adornos Antrittsvorlesung »Die Aktualität der Philosophie«, die er im selben Jahr an derselben Universität gehalten hat, Horkheimers 1940 veröffentlichter Aufsatz »Die gesellschaftliche Funktion der Philosophie« und schließlich Adornos 1962 veröffentlichter Aufsatz »Wozu noch Philosophie?«. Beide, Adorno und Horkheimer, haben im Verlaufe ihrer Karrieren unzählige Arbeiten veröffentlicht, die Auswahl der untersuchten Texte ist folglich auch hier notwendig auf für das Thema besonders repräsentative beschränkt. Mehr noch als in den anderen Kapiteln ließen sich die Zusammenhänge, die hier

157 Mit Clemens Albrecht, Günter C. Behrmann, Michael Bock und Harald Homann - den Autoren von Die intellektuelle Gründung der Bundesrepublik. Eine Wirkungsgeschichte der Frankfurter Schule (1999) - wird hier davon ausgegangen, dass die Kritische Theorie sich in den 196oer-Jahren mit Rückbezug auf die Texte der 193oer-Jahre konstituiert hat. »Was als Kritische Theorie in den 6oer Jahren verbreitet wurde, waren nicht die jüngsten Veröffentlichungen, sondern die kritische Theorie aus den 3oer Jahren« (Albrecht et al. 1999: 560). 
interessieren, auch an anderen Texten, Büchern und Projekten aufzeigen, allen voran an den groß angelegten Studien über Autorität und Familie, die im Auftrag des Instituts für Sozialforschung 1936 publiziert worden sind, sowie am Forschungsprojekt The Authoritarian Personality, das an der University of California durchgeführt worden ist und 1950 publiziert wurde. Sie sollen an dieser Stelle zumindest kurz erwähnt werden: »Wenn wir die psychologischen Determinanten der Ideologien kennen «, so steht im Vorwort von The Authoritarian Personality, „wissen wir immer noch nicht, welches die wahre Ideologie ist; wir können nur ein paar Hindernisse aus dem Weg räumen, auf dem wir sie suchen « (Adorno 1995 [1950]: 15). Die Studie war »an der Hypothese orientiert, daß die politischen, wirtschaftlichen und gesellschaftlichen Überzeugungen eines Individuums häufig ein umfassendes und kohärentes, gleichsam durch eine >Mentalität oder einen >Geist` zusammengehaltenes Denkmuster bilden, und daß dieses Denkmuster Ausdruck verborgener Züge der individuellen Charakterstruktur ist « (ebd.: 1). Worum Seidel gerungen hat, nämlich das Bewusstsein zu objektivieren, wird hier gewissermaßen zum wissenschaftlichen Programm: Der Geist bzw. das Bewusstsein wird insofern zum Untersuchungsgegenstand, als dass er bzw. es als ein »Ausdruck « der politischen, wirtschaftlichen und gesellschaftlichen Überzeugungen verstanden und verhandelt wird. Im Vorwort zu Studien über Autorität und Familie schreibt Horkheimer:

Nicht bloß erfährt der Einzelne in ihrem Kreis [dem der Familie, MD] zuerst den Einfluss der kulturellen Lebensmächte, so dass seine Auffassung der geistigen Inhalte und ihre Rolle in seinem seelischen Leben wesentlich durch dieses Medium bestimmt ist, sondern die patriarchalische Struktur der Familie in der neueren Zeit wirkt selbst als entscheidende Vorbereitung auf die Autorität in der Gesellschaft, die der Einzelne im späteren Leben anerkennen soll. (Horkheimer 1936: VIII)

Die patriarchale Familie wird als Ort beschrieben, wo die »geistigen Inhalte « allererst bestimmt werden. Es gehöre, schreibt Horkheimer, schon seit mehreren Jahren »zu den Aufgaben des Instituts [für Sozialforschung, MD], den Zusammenhang zwischen den verschiedenen Bereichen der materiellen und geistigen Kultur zu erforschen " (Horkheimer 1936: VII-VIII). Dass diese Aufgaben politisch motiviert sind, wird vor allem im Vorwort von The Authoritarian Personality deutlich. »Im Mittelpunkt des Interesses stand das potentiell faschistische Individuum, ein Individuum, dessen Struktur es besonders empfänglich für antidemokratische Propaganda macht « (Adorno 1995 [1950]:1). Die Autoren der Studie sind der Meinung, »dass keine politischsoziale Strömung unsere traditionellen Werte und Institutionen so gravierend 
bedroht wie der Faschismus, und dass er, wenn die psychologischen Kräfte erkannt sind, die ihn begünstigen, schließlich besser zu bekämpfen ist« (ebd.). In diesen Sätzen ist die weiter oben erwähnte Diskrepanz angesprochen, die zwischen den Erneuerungsstrategien des Wiener Kreises und denjenigen der Kritischen Theorie liegt: Wissenschaftliche Forschung - und wie weiter unten deutlich wird: auch die Philosophie - wird hier explizit in den Dienst der Gesellschaft gestellt. In den vom Institut für Sozialforschung lancierten Studien wird mit psychologischen und soziologischen Mitteln die Bildung von Ideologien untersucht und dies mit dem Anspruch verbunden, diese Ideologien verändern und überwinden zu können.

Diese Programmatik wird in der Kritischen Theorie durch eine Kooperation mit den empirischen Sozialwissenschaften einerseits und durch eine Abgrenzung gegenüber der Wissenssoziologie andererseits verfolgt. Horkheimer und Adorno nehmen die an Lukács und Korsch aufgezeigte Gedankenfigur der gegenseitigen Durchdringung von Theorie und Praxis auf, um davon ausgehend ein traditionelles Philosophieverständnis zu aktualisieren: die Philosophie als Instanz der Kritik an der Gesellschaft.

\section{Positionierung in der philosophischen Tradition}

Als Horkheimer $193^{1}$ die Leitung des Instituts für Sozialforschung in Frankfurt am Main übernahm, trat er gleichzeitig den von der Philosophischen Fakultät neu geschaffenen Lehrstuhl für Sozialphilosophie an. ${ }^{158}$ Nach dem Gründungsdirektor des Instituts - dem Austromarxisten und Nationalökonomen Carl Grünberg - übernimmt also erstmals ein Lehrstuhlinhaber der Philosophie die Leitung des Instituts. Dass sich das Institut für Sozialforschung in der Folge zunehmend als eine philosophische Einrichtung verstehen wird, wird an Horkheimers programmatischer Antrittsrede deutlich. »Horkheimer als Philosoph (während Grünberg Historiker [sic!] gewesen war) setzte in seiner Antrittsrede neue Akzente im Sinne einer Verlagerung der Institutsarbeit von der Beschäftigung mit dem historischen Materialismus als >Wissenschaft< hin zur Entwicklung einer durch empirische Untersuchungen ergänzten >Sozialphilosophie« (Anderson 1978 [1976]:55). Wie der Titel besagt, stellt Horkheimer in dieser Rede - gemäß Rolf Wiggershaus ein »Meisterwerk bedächtiger Stilisierung« (Wiggershaus 1986:51) - die Aufgaben,

158 Es handelte sich dabei in Deutschland um den einzigen Lehrstuhl für Sozialphilosophie (Wirkus 1996: 148). »Alle anderen Ordinariate wurden für Philosophie, Soziologie, Politische Soziologie, Nationalökonomie, Staatswissenschaften usw. ausgeschrieben« (ebd.). 
die das Institut für Sozialforschung zukünftig zu bewältigen habe, in einen unmittelbaren Zusammenhang mit der Sozialphilosophie.

Dass der Philosoph Horkheimer in den für das Institut bisher bestimmenden Disziplinen - Nationalökonomie und Soziologie - nicht ausgebildet war, brachte ihn, wie Michael Bock es ausdrückt und entlang einiger Passagen aus Horkheimers Antrittsvorlesung aufzeigt, »in nicht geringe Verlegenheit« (Bock 1999: 45). Bocks Beobachtung, »dass bei Horkheimer so gut wie keine Rezeption oder Auseinandersetzung mit der fachwissenschaftlichen Nationalökonomie und Soziologie der letzten hundert Jahre stattfindet« (ebd.: 43), wird auch von Helmut Dubiel bestätigt: »Mit der fachwissenschaftlichen Soziologie der Weimarer Republik im engeren Sinne waren offenbar weder Horkheimer noch andere Mitarbeiter seines Kreises besonders vertraut« (Dubiel 1978: 156). Dass die Soziologie von Horkheimer (und anderen Vertretern der Kritischen Theorie) kaum rezipiert worden ist, ${ }^{159}$ ist in der hier eingenommenen Perspektive bezeichnend: Es verweist darauf, dass Horkheimer zwar argumentativ auf die Soziologie zurückgreift, seine eigene Position aber nicht innerhalb der Soziologie verortet, sondern diese auf der Grundlage seiner eigenen Disziplin, d.h. auf der Grundlage philosophischer Prämissen, konzipiert. ${ }^{160}$

In Horkheimers Antrittsrede, so soll im Folgenden gezeigt werden, wird eine ambivalente Bewegung sichtbar: Auf der einen Seite positioniert er die Gesellschaftstheorie als neue Form der Philosophie, auf der anderen Seite wiederum

159 Insbesondere Bocks Ausführungen münden diesbezüglich in einer scharfen Kritik an Horkheimer: Es wirke befremdlich, so moniert Bock, »wenn Horkheimer sämtliche soziologische Richtungen ohne Skrupel der >traditionellen Theorie einordnet, indem er die bestehenden Unterschiede schlicht für irrelevant erklärt« (Bock 1999: 47). Horkheimers Gesellschaftstheorie »lebt mindestens teilweise von einer an die Grenze der Seriosität reichenden Missachtung der nationalökonomischen und soziologischen Diskussionslage« (ebd.: 55). Bock veranschaulicht an zwei Beispielen aus der zeitgenössischen Soziologie (Siegfried Landshut mit Kritik der Soziologie und Hans Freyer mit Soziologie als Wirklichkeitswissenschaft), inwiefern Horkheimers »eigenmächtiger Umgang mit der soziologischen Tradition« sich wirkungsgeschichtlich als vorteilhaft erweist: So gebe es »keine womöglich kompromittierenden Stellungnahmen zu den kongenialen MarxInterpreten Freyer und Landshut mit ihrer auf die Überwindung der Klassengesellschaft zielenden Soziologie« (ebd.: 54). Horkheimer, so könnte gefolgert werden, verortet sich also gerade aufgrund seiner Missachtung der soziologischen Literatur in der Philosophie.

16o In diesem Aspekt liegt für Bock »einer der Gründe für den geistigen Bruch mit der Gründungsära des Instituts für Sozialforschung« (Bock 1999: 44). 
grenzt er sich dezidiert von einer möglichen Aufhebung der Philosophie in die empirischen Sozialwissenschaften ab. ${ }^{161}$

\section{Zusammenschluss der Philosophie mit den empirischen Sozialwissenschaften}

An der zeitgenössischen Sozialphilosophie kritisiert Horkheimer, dass diese sich »polemisch zum Positivismus« verhalte. Die Philosophie - an dieser Stelle verwendet er bezeichnenderweise den allgemeineren Begriff Philosophie statt Sozialphilosophie - setze den »feststellbaren Tatsächlichkeiten [...] Ideen, Wesenheiten, Totalitäten, selbstständige Sphären des objektiven Geistes, Sinneinheiten, Volksgeister als ebenso ursprüngliche, ja als >echtere< Seinsbestände gegenüber« (Horkheimer 1931: 27). Die Sozialphilosophie bzw. die Philosophie setze sich also von empirischen Tatsachen ab, indem sie einen davon gesonderten Bereich behaupte. Genau darin liege deren »Mangel «- und dieser Mangel müsse überwunden werden (ebd.: 27). Es geht Horkheimer also um die Einbeziehung empirischer Forschung in die Philosophie. Dadurch, so die Implikation, könne die philosophische Tradition erweitert und >verbessert< werden. Dem möglichen Einwand, dass doch die einzelwissenschaftliche Soziologie und nicht die Philosophie mit der »Untersuchung der bestimmten Formen der Vergesellschaftung zu tun habe« (ebd.: 28), begegnet Horkheimer mit dem Argument, dass dieser Ansicht »ein nicht mehr haltbarer Begriff der Philosophie« (ebd.) zugrunde liege:

Wie man auch die Grenzen zwischen einzelwissenschaftlicher Fachsoziologie und Sozialphilosophie ziehen mag, ich glaube, ein großes Maß an Willkür wäre dabei unvermeidlich, eines ist gewiss: wenn das sozialphilosophische Denken über das Verhältnis von Individuum und Gesellschaft, über den Sinn von Kultur, über den Grund der Gemeinschaftsbildung, über die Gesamtstruktur des gesellschaftlichen Lebens, kurz über die großen und prinzipiellen Fragen gleichsam als Bodensatz in dem Reservoir der gesellschaftlichen Probleme zurückgeblieben sein sollte, nachdem diejenigen Fragen ausgeschüttet worden sind, die man in konkreten Untersuchungen vorwärtsbringen kann, z.B. eben die der Verklärung, um ihre intellektuelle Fruchtbarkeit aber wäre es geschehen. (ebd.: 28, Herv. MD)

Horkheimers Argumentation ist bezüglich der darin angewandten Aktualisierungsstrategien äußerst aufschlussreich: Mit dem Argument, die Philosophie würde ihre »intellektuelle Fruchtbarkeit« verlieren, wenn sie lediglich

161 In der hier eingenommenen Perspektive ist es also keineswegs so, dass es Horkheimer schlicht um die »Aufhebung der Philosophie in die Gesellschaftstheorie« ging, wie Jürgen Habermas schreibt (Habermas 1986: 164). 
als »Bodensatz« der empirischen Forschung fungieren würde, plädiert er für eine konstitutive Verbindung zwischen den empirischen Sozialwissenschaften und der Philosophie. Die unhaltbare Trennung zwischen »Einzelforscher« und »Philosoph« werde gegenwärtig »durch den Gedanken einer fortwährenden Durchdringung und Entwicklung von philosophischer Theorie und einzelwissenschaftlicher Praxis überwunden «. ${ }^{162}$ In der Folge stellt Horkheimer die Interdisziplinarität als jene neue Form dar, mit der der Mangel der Philosophie zu beheben sei:

Vielmehr kommt es heute darauf an, und ich stehe mit dieser Ansicht gewiß nicht allein, auf Grund aktueller philosophischer Fragestellungen Untersuchungen zu organisieren, zu denen Philosophen, Soziologien, Nationalökonomen, Historiker, Psychologen in dauernder Arbeitsgemeinschaft sich vereinigen und das gemeinsam tun, was auf anderen Gebieten im Laboratorium einer allein tun kann, was alle echten Forscher immer getan haben: nämlich ihre aufs Große zielenden philosophischen Fragen an Hand der feinsten wissenschaftlichen Methoden zu verfolgen, die Fragen im Verlauf der Arbeit am Gegenstand umzuformen, zu präzisieren, neue Methoden zu ersinnen und doch das Allgemeine nicht aus den Augen zu verlieren. (ebd.: 29-30)

Ähnlich wie es am Beispiel des Wiener Kreises deutlich geworden ist, verlagert Horkheimer die >Fruchtbarkeit $\triangleleft$ der Philosophie in die empirischen Wissenschaften. Im Unterschied zu den Erneuerungsstrategien des Wiener Kreises aber, in denen die Philosophie mit den empirischen Wissenschaften identifiziert wird, argumentiert er für eine Kooperation zwischen Philosophie und empirischen Sozialwissenschaften und hält damit an der Unabhängigkeit der Philosophie fest.

Horkheimer betont, dass er dem Ruf, dieses Forschungsinstitut zu leiten, gefolgt sei im Hinblick »auf diese für Philosophie und Empirie gleich wichtige Möglichkeit und nicht, um die Tatsachenforschung zur ancilla philosophiae zu machen $[. .$.$] « (ebd.: 31). Dass es sich beim interdisziplinär angelegten$ Forschungsprogramm des Instituts aber letztlich um ein philosophisches Programm handelt, begründet und legitimiert er mit dem Verweis auf die

162 Ein gutes Beispiel für diese gegenseitige Durchdringung sei die »Beziehung zwischen Naturphilosophie und Naturwissenschaft« (Horkheimer 1931: 29). Horkheimer nimmt hier in affirmativer Weise jene zeitgenössischen Bestrebungen auf, die u.a. von den Vertretern des Wiener Kreises vorangetrieben wurden. Dass sowohl der Wiener Kreis als auch die Kritische Theorie >Interdisziplinarität $<$ zum neuen Schlagwort philosophischer Forschung stilisieren, ist mit Blick auf ihre Argumentationsstrategien bezeichnend: Im Unterschied zu Husserls Abgrenzungspraktik ist sowohl in der Fundierungsstrategie des Wiener Kreises als auch in der Kooperationsstrategie der Kritischen Theorie der Zusammenschluss mit den Wissenschaften ein antreibendes Element. 
philosophische Tradition selbst: So sei der am Institut zu erforschende »Zusammenhang zwischen dem wirtschaftlichen Leben der Gesellschaft, der psychischen Entwicklung der Individuen und den Veränderungen auf den Kulturgebieten« eine »aktuelle Fassung ältester und wichtigster philosophischer Probleme [...] « (ebd.: 32). Bei diesen Fragen handele es sich letztlich um die »alten Fragen nach dem Zusammenhang von besonderer Existenz und allgemeiner Vernunft, von Realität und Idee, von Leben und Geist, nur eben auf die neue Problemkonstellation bezogen« (ebd.). Letztlich, so legt Horkheimer nahe, betreibe das Forschungsinstitut nichts anders als Philosophie im ursprünglichen Sinn. ${ }^{163}$

Er begründet und legitimiert diesen Befund wiederum mit der philosophischen Tradition. Er argumentiert dafür, dass das Motiv der Gesellschaft immer schon ein entscheidendes Element der Philosophie und ihrer Geschichte gewesen sei. Besonders prägnant ist diese Argumentationsstrategie in seinem zehn Jahre später verfassten Aufsatz »Die gesellschaftliche Funktion der Philosophie« formuliert: »Wer die neuere Philosophie studiert, nicht bloß in durchschnittlichen Kompendien, sondern indem er selbst ihrer Geschichte nachgeht, wird das gesellschaftliche Problem als ein sehr entscheidendes Motiv in ihr erkennen « (Horkheimer 1941:346). Bereits Aristoteles habe gesagt, so erhärtet er sein Argument, dass das höchste Glück - die Selbstbetrachtung der Seele - »nur auf einer spezifischen materiellen Basis, also unter bestimmten gesellschaftlichen und ökonomischen Bedingungen, möglich ist « (ebd.). Werde die Philosophie und deren Geschichte unter materiellen Aspekten interpretiert, so sehe man - dies Horkheimers Folgerung -, dass die Gesellschaft schon immer ein entscheidendes und fundierendes Element der Philosophie gewesen sei. Die Gesellschaft wird von ihm zu einem vorrangigen philosophischen Problem erklärt. Das »gesellschaftliche Thema« (ebd.) wird also nicht nur als eines unter anderen philosophischen Problemen dargestellt, sondern - weit radikaler - als das für die Philosophie vorherrschende Problem. Umgekehrt wird dadurch die Philosophie im Medium der Sozialwissenschaften verstanden. »Die Philosophie muss «, so fasst Jürgen Habermas diesen Aspekt, »solange sie nicht verwirklicht werden kann, in ein anderes Medium übertreten, um nicht zur Ideologie zu verkommen - und für Horkheimer sollten

163 Dass dieser Aussage eine »philosophische Überzeugung « zugrunde liegt, die keineswegs von allen Institutsmitgliedern (auch nicht von Adorno, wie weiter unten deutlich werden wird) geteilt wurde, betont z.B. Jürgen Habermas: »Daß Horkheimers Philosophie in dieser Zusammenarbeit mit Ökonomen, Psychologen, Juristen, Historikern und Soziologen, Musik- und Literatursoziologen vor allem, aufgehen sollte, hatte seinen Grund in einer philosophischen Überzeugung, die andere Institutsmitarbeiter keineswegs teilten die jedenfalls für deren Arbeit nicht das primum movens war« (Habermas 1986: 163). 
die im Brennspiegel der kritischen Gesellschaftstheorie gebündelten, eingeschmolzenen und zugleich erneuerten Sozialwissenschaften dieses Medium sein « (Habermas 1986: 164).

Diese Kooperation wird nicht nur mit den empirischen Sozialwissenschaften generell, sondern auch mit der Soziologie hergeleitet. Konzis bringt dies Adorno in seiner Vorlesung Philosophie und Soziologie von 196o auf den Punkt. In der ersten Stunde sagt er:

Ich möchte $[. .$.$] versuchen, diejenigen von Ihnen, die von der einen oder der$ anderen Seite herkommen, ein wenig über die Problematik dessen aufzuklären, daß nun also hier an dieser Universität in einer gewissen Personalunion sowohl bei Herrn Horkheimer wie bei mir zwei Fächer sich vereinigt finden, die im Sinn eines jedenfalls nach beiden Seiten sehr weit verbreiteten Vorurteils eigentlich inkompatibel sind und nichts miteinander zu tun haben. (Adorno 2011: 9-10)

Adorno stößt durch dieses Vorgehen dann aber auf ein Problem, und zwar eines, »das sowohl soziologisch wie philosophisch von erheblicher Relevanz ist und dem beide Disziplinen sich nicht entziehen können: nämlich auf das Problem der Idee der Wahrheit auf der einen Seite und auf der anderen Seite auf [das] der gesellschaftlichen Determination von Erkenntnis überhaupt« (Adorno 2011: 10).

Zusammenfassend kann festgehalten werden, dass Horkheimer und Adorno die zentrale marxistische Einsicht der gegenseitigen Durchdringung von Philosophie und Gesellschaft mit dem Ziel aufnehmen, die Gesellschaft zum privilegierten philosophischen Bereich zu erklären. Indem das interdisziplinär angelegte Forschungsprogramm des Instituts jedoch als ein philosophisches Programm präsentiert wird, ordnen sie die neu zu entwickelnde Gesellschaftstheorie explizit in die Tradition der Philosophie ein. ${ }^{164}$

\section{Abgrenzung gegenüber der Wissenssoziologie}

Mannheims Wissenssoziologie spielt - so wurde zu Beginn des Kapitels im Zusammenhang mit Seidel angedeutet - für die philosophische Positionierung der Kritischen Theorie eine zentrale Rolle. ${ }^{165}$ In der Auseinandersetzung von

\footnotetext{
164 Der Anspruch nach der Überwindung der Metaphysik ist in allen drei Beispielen sichtbar. Aktualisierungsstrategisch erweist sich dies als zentral (siehe dazu insbesondere S. 193-194).

165 Wie Adorno und Horkheimer das komplizierte und komplexe Verhältnis zwischen Soziologie, Sozialwissenschaften und Philosophie in ihren zahlreichen Schriften bestimmen und definieren, ist weder einheitlich, noch bleibt es im Verlaufe ihres Schaffens gleich. Vielmehr ist diese Verhältnisbestimmung sowohl auf institutioneller als auch auf ideeller Ebene selbst Teil der Entstehung der Kritischen Theorie (siehe Demirović 1999).
} 
Horkheimer und Adorno mit Mannheim wird eine Strategie der Abgrenzung ähnlich wie bei Husserl deutlich. ${ }^{166}$ Indem Horkheimer und Adorno der Wissenssoziologie Mannheims Lücken und Fehler nachweisen, argumentieren sie für die Wichtigkeit einer genuin philosophischen Perspektive. ${ }^{167}$

1929 erscheint Mannheims Buch Ideologie und Utopie. »Die Philosophen «, so sagt Mannheim zu Beginn des Buches, »haben sich allzulange bloß mit ihrem eigenen Denken befasst« (Mannheim 1978 [1929]: 3). Diese gewissermaßen idiosynkratische Ausrichtung philosophischen Denkens lehnt Mannheim ab. Sein Buch befasse sich »mit dem Problem, wie Menschen wirklich denken« (ebd.). Er stellt klar, dass das Denken der Philosophen lediglich ein »Typus des Denkens« und »nur unter ganz bestimmten Umständen anwendbar« ist (ebd.). Er nimmt also eine soziologische Perspektive auf das Denken - und somit auch auf das philosophische Denken - ein. Wie Martin Jay betont, sah sich die Kritische Theorie, jeden Anspruch auf absolute Wahrheit zurückweisend, häufig mit denselben Problemen konfrontiert, nach deren Lösung auch die Wissenssoziologie suchte (Jay 1973: 87-88). Weder Horkheimer noch andere Vertreter der Kritischen Theorie seien jedoch je bereit gewesen, Mannheim »darin zu folgen, den Marxismus nur als eine unter anderen Ideologien zu >entlarven « (Jay 1973: 88). Mannheim, so Jay weiter, schien mit seiner Behauptung, alles Wissen sei sseinsgebunden<, die fundamentale marxistische Unterscheidung zwischen richtigem und falschem Bewusstsein zu untergraben - »eine Unterscheidung, an der die Kritische Theorie ausdrücklich festhielt« (ebd.). Demnach ist einer der wesentlichen Vorwürfe aus Sicht der Kritischen Theorie an Mannheim, dieser würde eine Abkehr von einer marxistisch geprägten Ideologiekritik praktizieren (Huke-Didier 1985: 39).

Dubiel geht in seinem Aufsatz Ideologiekritik versus Wissenssoziologie (1975) den »immanent theoretischen Gründe[n] « für die »übergroße und anhaltende Aufmerksamkeit« nach, die die Vertreter der Kritischen Theorie der Wissenssoziologie Mannheims widmeten, und stellt fest: »Mannheims Wissenssoziologie diente den Vertretern der kritischen Theorie gerade in den

166 Nebst Horkheimer haben auch Marcuse und Adorno ihre Position dezidiert von der Wissenssoziologie abzugrenzen versucht. Zum Beispiel Marcuse 1982 [1929]; Adorno 1977 [1955].

167 Sabine Maasen formuliert die Kritik der Kritischen Theorie an Mannheim wie folgt: »Die Kritik der Frankfurter Schulde am Mannheim'schen Ansatz zielt auf dessen PseudoRadikalität: Das Konzept der gesellschaftlichen Totalität sei erstens idealistische Metaphysik, zweitens bleibe der Zusammenhang zwischen Bewusstsein und sozialer Existenz vage und drittens sei der totale Ideologiebegriff ohne kritisches Potential, da er auf einem inhaltsleeren Kriterium, der bloßen Perspektivität von Ideen beruhe« (Maasen 2009: 27). 
Kernpunkten ihres Selbstverständnisses als Kontrastfolie ihrer positionellen Selbstdefinition « (Dubiel 1975: 223). ${ }^{168}$ Im gemeinsam verfassten Aufsatz Philosophie und Kritische Theorie schreiben Marcuse und Horheimer: »Die Soziologie, welche sich nur mit den Bedingtheiten beschäftigt, hat es nicht mit der Wahrheit zu tun; ihr in manchem nützliches Geschäft verfälscht das Interesse und das Ziel der kritischen Theorie (Horkheimer/Marcuse 1970 [1937]: 643). Die »Sorge« der Kritischen Theorie hingegen sei, »daß die Wahrheiten nicht verloren gehen, auf die das vergangene Wissen schon hingearbeitet hatte« (ebd.). Im Zusammenhang mit einer Abgrenzung gegenüber der Wissenssoziologie bringen Marcuse und Horkheimer hier das Selbstverständnis der Philosophie als jener Wissenschaft hervor, die mit Wahrheit verbunden ist. Die Kritische Theorie, so die Implikation, kümmere sich im Gegensatz zur Wissenssoziologie um diesen Aspekt. »Die Auseinandersetzung der kritischen Theorie mit der Philosophie ist an dem Wahrheitsgehalt der philosophischen Begriffe und Probleme interessiert: sie setzt voraus, daß Wahrheit wirklich in ihnen enthalten ist. Das Geschäft der Wissenssoziologie dagegen betrifft immer nur die Unwahrheiten, nicht die Wahrheiten der Philosophie« (ebd.: 640). Hier wird offensiv für den philosophischen Gehalt der Kritischen Theorie argumentiert und dieser Gehalt mit dem Begriff der Wahrheit verbunden. ${ }^{169}$

Eine ähnliche argumentative Bewegung ist auch bei Horkheimer in dessen Aufsatz »Ein neuer Ideologiebegriff?« zu beobachten. Mannheim falle - so die Stoßrichtung der Argumentation - letztlich in genau jene metaphysischen Strukturen zurück, die er mit »einigen Stücken aus der Rüstkammer des Marxismus « zu kritisieren beabsichtigt hatte: »Diese grundstürzende, alles >dynamisch auflösende Soziologie kommt [...] ohne den Halt einer dogmatischen Metaphysik nicht aus, vielmehr hebt sie die Zerstörung aller absoluten philosophischen Sinnforschungen damit wieder auf, dass

168 In Anlehnung an diese Feststellung Dubiels möchte Tae-Kook Jeon in seiner Dissertation Karl Mannheims Ideologietheorie und ihr Verhältnis zur Kritischen Theorie der Frankfurter Schule zeigen, dass »die `Kontrastfolie`, mit der die Frankfurter Schule ihre Kritische Theorie von der Lehre Mannheims abzugrenzen versuchte, nicht begründet ist, weil die Kritische Theorie in ihrem Kernpunkt die Mannheimsche Lehre aufnahm« (Jeon 1984: 4). Jeon kehrt somit die Hauptkritik, die Horkheimer, Marcuse und Adorno an Mannheim übten - dessen Abweichung vom Marxismus -, in ihr Gegenteil: Demnach sei nicht die Kritische Theorie, sondern die »Lehre Mannheims im Wesentlichen die Weiterentwicklung der Marxschen Lehre« (ebd.).

169 Auch Dubiel stellt im betreffenden Aufsatz fest, dass die Vertreter der Kritischen Theorie in ihrer Kritik an der Wissenssoziologie auf den Begriff der Wahrheit zurückgreifen: »Es wird [in vielen Äußerungen der >Frankfurter< über die Mannheim'sche Wissenssoziologie, MD] dabei in der Regel die Formulierung verwendet, dass in jeder ideologischen Aussage immer auch Wahrheit enthalten sei« (Dubiel 1975: 232). 
sie sich selbst als ihre fortgeschrittenste Form empfiehlt« (Horkheimer 1987 [1930]: 281).

Horkheimer entwickelt sein eigenes Philosophieverständnis entlang einer Abgrenzung zur Wissenssoziologie. Zehn Jahre nach besagtem Aufsatz nimmt er die Kritik an Mannheim in seinem Aufsatz »Die gesellschaftliche Funktion der Philosophie« (1940) nämlich erneut auf. Mit dem Verweis auf Mannheims Ideologie und Utopie wendet er sich hier gegen jene Auffassungen, die die Philosophie mit Ideologie gleichsetzen. Diese Auffassungen behaupten gemäß Horkheimer »philosophisches Denken, oder richtiger: Denken als solches sei bloßer Ausdruck einer spezifischen gesellschaftlichen Situation « (Horkheimer 1940: 342). Horkheimer betont zwar, dass diese marxistische Perspektive bis zu einem gewissen Grade richtig sei, denn »viele der heute verbreiteten Ideen enthüllen sich als bloße Illusionen, wenn man sie von ihrer gesellschaftlichen Basis her betrachtet« (ebd.), dennoch setzt er sich von einer wissenssoziologischen Perspektive ab. »Man muß tiefer gehen«, sagt er, »und sie [die heute verbreiteten Illusionen, MD] aus dem historischen Prozeß entwickeln, aus dem die sozialen Gruppen selbst zu erklären sind « (ebd.: 342-343). Die Soziologie, so sagt Horkheimer dezidiert, »bleibt unzureichend. Wir brauchen eine umfassende Theorie der Geschichte« (ebd.: 343). Der Verlust des geschichtlichen Aspekts, der in der Wissenssoziologie sichtbar werde, berge die Gefahr, »bedeutsame Philosopheme mit unbedeutenden oder jedenfalls nicht entscheidenden Gruppen in Beziehung zu setzen oder auch das Gewicht einer spezifischen Gruppe im Ganzen der Gesellschaft und damit den gegebenen Kulturzusammenhang misszudeuten « (ebd.). Im Zusammenhang mit seiner Absetzung von der Wissenssoziologie betont Horkheimer also die Wichtigkeit der Geschichte für die Kritik an bestehenden Verhältnissen. ${ }^{170}$

Auch hier wird der Wahrheitsbegriff verwendet, um die Position der Kritischen Theorie von der Wissenssoziologie abzugrenzen. So liege der »wesentliche Einwand« gegen eine Soziologisierung des Denkens darin, dass

170 Es könnten vermutlich ähnliche Argumentationsstrategien in Bezug auf das Verhältnis zwischen Philosophie und Geschichte gefunden werden, wie sie hier in Bezug auf das Verhältnis zwischen Philosophie und Soziologie herausgearbeitet werden. So fordern Horkheimer und Adorno zwar in dezidierter Weise eine Geschichtsphilosophie, ohne jedoch die Geschichtswissenschaften konstruktiv in ihre Theorie aufzunehmen bzw. ihren Standpunkt in der Geschichtswissenschaft zu verorten. Herbert Schnädelbach, dessen Habilitation erst von Adorno und nach dessen Tod von Habermas begutachtet wurde, benennt Adornos Überlegungen zur Geschichte als »Geschichtsphilosophie ohne Geschichte« (Schnädelbach 2008: 131). Die Geschichte komme bei Adorno überhaupt nicht vor. Wo in der Dialektik der Aufklärung noch eine Geschichte erzählt werde - nämlich »die Geschichte hinter der Geschichte, die wahre Geschichte« (ebd.: 132) -, komme die Geschichte in der Negativen Dialektik gar nicht mehr vor (ebd.: 133). 
diese Denkrichtung philosophische Wahrheit und damit Wahrheit überhaupt verleugne: »Die stereotype Anwendung des Ideologiebegriffs auf jedes Denkgebilde beruht letztlich auf der Vorstellung, daß es keine philosophische und damit überhaupt keine Wahrheit für die Menschheit gebe, daß alles Denken sseinsgebunden< sei« (ebd.: 343). Hier wird exakt das Dilemma aufgenommen, aus dem Seidel analytisch keinen Ausweg weiß: Wird jedes Denken als Ideologie aufgefasst, fehlt, so lässt sich Bewußtsein als Verhängnis verstehen, jegliche Grundlage, von der aus gedacht werden kann. Mannheim löst das Problem insofern, dass er sich auf einen soziologischen Standpunkt stellt und davon ausgehend den >Geist bzw. das Bewusstsein soziologisiert. Analog dazu lösen Horkheimer und Adorno das Problem so, dass sie sich - mit dem Argument, dass an der Wahrheit festgehalten werden müsse - zu einem philosophischen Standpunkt bekennen. Horkheimer bringt gegen die Relativierung von Wahrheit das Argument vor, dass eine solche Perspektive im »philosophischen Skeptizismus und Nihilismus « münde (ebd.: 341). Gleichzeitig parallelisiert er den philosophischen Skeptizismus und Nihilismus mit der Auflösung der Philosophie in die Soziologie: »Wir erkennen mühelos«, sagt er, »daß diese Schule [die Mannheim-Schule, MD], die schließlich darauf hinausläuft, die Philosophie in eine Spezialwissenschaft, in Soziologie aufzulösen, nur die skeptizistische Position wiederholt, die wir bereits kritisiert haben« (ebd.: 344). Eine Verleugnung philosophischer Wahrheit, d.h. die Auflösung der Philosophie in die Soziologie, darf laut Horkheimer jedoch nicht propagiert werden. Die Wissenssoziologie sei keineswegs darauf angelegt, so moniert er, die "gesellschaftliche Funktion der Philosophie zu erklären, sondern hat vielmehr ihrerseits eine solche: dem in die Zukunft weisenden Denken die Courage abzukaufen, seine praktische Tendenz zu unterbinden« (ebd.: 344 ).

Horkheimer bringt mit seiner Kritik - ex negativo - ein bestimmtes philosophisches Selbstbild hervor: Wenn er erstens schreibt, dass viele neuere (wissenssoziologisch orientierte) Autoren die Philosophie als »Dienerin « und nicht mehr als »Kritikerin« der Wissenschaft und der Gesellschaft allgemein verstehen würden, erzeugt er ein Selbstbild der Philosophie als Kritikerin der Wissenschaften. Wenn er zweitens schreibt, dass diese Autoren die These vertreten würden, dass »ein Denken, das die herrschenden Formen wissenschaftlicher Betätigung und damit den Horizont der gegenwärtigen Gesellschaft transzendiert«, unmöglich sei, entwirft er ein Selbstbild, das der Philosophie ein Vermögen zur Transzendierung zuschreibt. Und wenn er drittens moniert, dass wissenssoziologische Positionen kaum das spezifisch Philosophische »enthüllen«, also dasjenige, was die Philosophie von den Einzelwissenschaften unterscheide, behauptet er etwas genuin und spezifisch Philosophisches, 
etwas, das sich von den anderen Disziplinen per se unterscheidet (Horkheimer 1941: 341).

Indem Horkheimer sich von wissenssoziologischen Perspektiven abgrenzt, verteidigt er eine `wirkliche Philosophie bzw. die philosophische Wahrheit. Wie Bernd Wirkus betont, hält Horkheimer »an einem traditionellen, d.h. absoluten Wahrheitsbegriff fest, der über jeder Kontingenz der geschichtlichen Veränderungen und Faktizitäten zu stehen scheint. In dieser unterschiedlichen Konzeption des Wahrheitsbegriffs entsteht einer der wesentlichen Unterschiede zwischen der Kritischen Theorie und der Position der Wissenssoziologie« (Wirkus 1996: 150). Dass Horkheimer sein eigenes Philosophieverständnis durch die Abgrenzung zu wissenssoziologischen Perspektiven entwickelt, wird auch auf der Ebene seiner Textkonzeption deutlich: er spricht unmittelbar nach seiner Kritik an der Wissenssoziologie seine berühmt gewordene Definition der Philosophie aus: »Die wahre gesellschaftliche Funktion der Philosophie liegt in der Kritik des Bestehenden« (ebd.: 344). Durch die Kritik an der Wissenssoziologie wird in Abhebung von dieser die Philosophie als jene Wissenschaft aktualisiert, die sich um die Wahrheit kümmert. Philosophie, Wahrheit und Kritik werden von Horkheimer intrinsisch miteinander verbunden.

\section{Neubestimmung: Die Philosophie als Instrument der Kritik}

Lukács und Korsch konzeptualisieren, so ist deutlich geworden, Philosophiekritik im Dienste des Marxismus: Ziel und Zweck philosophischer Selbstkritik lägen in der gesellschaftlichen Veränderung. Lukács und Korsch >re-philosophieren< den Marxismus, indem sie ihn als Instrument konzeptualisieren, mit dem die (bürgerliche) Philosophie kritisiert werden kann. Diesen Aspekt nehmen Horkheimer und Adorno auf, um ausgehend vom Marxismus eine neue Bestimmung für die Philosophie im Allgemeinen zu konfigurieren. Das marxistische Ziel einer Umwälzung der Gesellschaft wird in der Kritischen Theorie zugunsten einer Neubestimmung der Philosophie zurückgestellt. ${ }^{171}$ »Das Selbstverständnis von Theorieproduktion«, so sagt Michael Buckmiller lakonisch, »nahm für die neue Generation von Mitarbeitern des Instituts [Horkheimer, Adorno etc., MD] in zunehmenden

171 Die Schwerpunktverlagerung eines politisch verstandenen Marxismus hin zur philosophischen Akademisierung kann auch an der Umbenennung der Zeitschrift des Instituts für Sozialforschung beobachtet werden: So stellt das Institut $193^{2}$ die Zeitschrift Archiv für die Geschichte des Sozialismus und der Arbeiterbewegung ein und ersetzte sie durch die Zeitschrift für Sozialforschung - ein laut Perry Anderson »unschuldiger« Name (Anderson 1978 [1976]: 55). 
Maße wieder die Züge der Philosophie an, weil es den aktiven Adressaten, die Arbeiterklasse, verloren hatte «(Buckmiller 1988: 173). Vor allem in den Jahren 1968-1973 wurde diese Entwicklung ausgehend von der marxistischen Studentenbewegung intensiv thematisiert und auch kritisiert. ${ }^{172}$ Die Kritische Theorie, die sich der Kritik jeglichen Systemdenkens verschrieben hat, habe sich - so der Vorwurf - selbst zu einem System, d.h. zur (bürgerlichen) Erkenntnistheorie mit universalem Anspruch, gewandelt. Die kritischen Theoretiker (allen voran Adorno) würden sich im Elfenbeinturm der Theorie verschanzen, statt ihre Theorie in der Praxis zu verwirklichen. ${ }^{173}$ »Aber der praktische Klassenstandpunkt«, so schreibt etwa Hans-Jürgen Krahl, einer der exponiertesten Studentenaktivisten und Schüler von Adorno, »[...] ist nicht theoretisch konstitutiv in die Theorie eingegangen « (Krahl 1971: 289). Mit welchen argumentativen Strategien - so die Frage, die sich in der hier eingenommenen Perspektive stellt - begründen Adorno und Horkheimer die Denkfigur der Durchdringung von Praxis und Theorie selbst als Philosophie?

Die Neubestimmung der Philosophie im Allgemeinen wird u.a. an der von Horkheimer und Adorno gemeinsam verfassten Schrift Dialektik der Aufklärung ${ }^{174}$ von 1944 deutlich. Es handelt sich dabei um eine breit angelegte Zeitdiagnose, die, so Alfons Söllner, »die Weltgeschichte als ganze zum Thema macht « (Söllner 1979: 190). Horkheimer und Adorno stellen dabei das Ziel gesellschaftlicher Veränderung zugunsten einer umfassenden Interpretation der Gegenwart zurück. Sie verwandeln die »materialistische Gesellschaftstheorie zurück in Geschichtsphilosophie« (ebd.). Die Vernunft, so eine Kernaussage der Dialektik der Aufklärung, äußere sich seit der Aufklärung nicht nur als Emanzipations-, sondern auch als Herrschaftsmittel. Die Durchsetzung der Vernunftprinzipien der Aufklärung hätte folglich keinen Befreiungsprozess in Gang gesetzt, sondern vielmehr einen Prozess der universellen Selbstzerstörung. Die Aufklärung falle in Mythologie zurück. Die Ursache für diesen Rückfall, so schreiben die Autoren im Vorwort, liege »bei der in Furcht vor der Wahrheit erstarrenden Aufklärung selbst« (Horkheimer/Adorno 2008

172 Siehe z.B. Habermas et al. 1968; Holz 1968; Heiseler/Steigerwald/Schleifstein (Hrsg.) 1970; Beyer 1971; Krahl 1971; Klüver/Wolf (Hrsg.) 1972.

173 Indem das Institut für Sozialforschung - so Martin Jay - »die faktische, ja sogar die mögliche Existenz eines historischen Subjekts bezweifelte, welches in der Lage war, eine vernünftige Gesellschaft herbeizuführen, warf das Institut die zentrale Prämisse in Marx' Werk von der Einheit von Theorie und Praxis endgültig über Bord. Die Konflikte seiner Mitglieder mit der deutschen Neuen Linken in den sechziger Jahren waren nur die Auswirkung dieser bereits eingetretenen Wandlung « (Jay 1981 [1973]: 343).

174 Die Dialektik der Aufklärung wurde als Rückzug der kritischen Gesellschaftstheorie von Horkheimer und Adorno in eine universalistische Geschichtsphilosophie interpretiert (z.B. Söllner 1979: 191). 
[1944]: 3-4). Aus diesen Thesen leiten sie eine neue Aufgabe für die nun nicht mehr »traditionelle«, sondern »kritische« Philosophie ab: Der Philosophie als kritischer Theorie komme die Rolle zu, diesem Prozess der Selbstzerstörung Einhalt zu gebieten, und zwar vermittels Selbstkritik, einer »negativen Dialektik«, wie Adorno diese Methode später auf den Begriff bringt. ${ }^{175}$ Der bedingungslose Glaube an die Vernunft, so Horkheimer und Adorno, birgt gesellschaftliches, politisches und soziales Zerstörungspotenzial. Sie machen um den Bezug zu Seidel aufzunehmen - das >Bewusstsein als Verhängnis $<$ zum Dreh- und Angelpunkt ihres Erneuerungsanspruchs, d.h., sie konzipieren ihre Einsicht in die prinzipielle Selbstzerstörung von Vernunft - paradoxerweise als neues philosophisches Programm. Die »geschichtsphilosophische Globalkonstruktion «, so Söllner, sei die »konsequente wissenschaftliche Realisierung dessen, was sich seit Anfang der 4oer Jahre als neue Funktionsbestimmung der Philosophie herausgebildet hatte« (Söllner 1979: 190).

Diese paradoxe Strategie wird im Folgenden an zwei Dokumenten nachvollzogen: erstens an Adornos Antrittsvorlesung, die er unter dem Titel »Die Aktualität der Philosophie « 1931 an der Universität Frankfurt am Main gehalten hat, und zweitens an seinem Artikel »Wozu noch Philosophie?«, der 1962 in der Zeitschrift »Merkur« veröffentlicht wurde.

\section{Ein Paradox produktiv machen: Philosophie trotz ihrer Unmöglichkeit!}

»Wer heute philosophische Arbeit als Beruf wählt«, so Adorno, »muß von Anbeginn auf die Illusion verzichten, mit der früher die philosophischen Entwürfe einsetzten: daß es möglich sei, in Kraft des Denkens die Totalität des Wirklichen zu ergreifen « (Adorno 1973b: 325). Adorno erteilt in seiner Antrittsvorlesung ${ }^{176}$ allen philosophischen Totalitätsentwürfen - allen voran Heideggers Fundamentalontologie - eine Absage (Kertesz 1999: 30). Seine Kritik richtet sich somit auch an Lukács' Verwendung des Totalitätsbegriffs. Indem Adorno den von Lukács in Geschichte und Klassenbewußtsein vertretenen Ansatz, Wahrheit durch Klassenherkunft zu begründen, zurückweist (Jay 1982: 74), formuliert er eine Kritik an den Prämissen des philosophischen Marxismus der 1920er-Jahre. Im Verlauf seiner Vorlesung wird zudem eine Kritik an Horkheimers Arbeitsprogramm des Instituts deutlich: Adorno

175 In diesem Zusammenhang ist Adornos berühmte Forderung zu verstehen, Auschwitz dürfe sich nie wieder wiederholen.

${ }_{17}$ Die Vorlesung wurde zu Lebzeiten Adornos nicht publiziert. Möglicherweise weil sie, wie Jay aus Briefen rekonstruiert, auf Vorbehalte gestoßen sei. Seine Zuhörer, so zitiert Jay Adorno, hätten nichts begriffen, und Mannheims Mutmaßung, er, Adorno, sei zum Wiener Kreis übergegangen, sei die dümmste aller dummen Reaktionen (Jay 1981 [1973]: 72). 
kritisiere, so Jay, »implizit die Behauptung aus Horkheimers Antrittsvorlesung, Sozialphilosophie und wissenschaftliche Forschung könnten sich vereinigen, um Erkenntnis vom gesellschaftlichen Ganzen zu gewähren« (ebd.: 73). Im Gegensatz dazu versteht Adorno die Philosophie und die Einzelwissenschaften als zwei grundsätzlich verschiedene Erkenntnisweisen. »Schlicht gesagt: Die Idee der Wissenschaft ist Forschung, die der Philosophie Deutung « (Adorno 1973b: 334). Ähnlich wie es am Beispiel von Husserl deutlich geworden ist, argumentiert also auch Adorno für einen prinzipiellen Unterschied zwischen Philosophie und Einzelwissenschaften.

In Auseinandersetzung mit den prominenten Philosophien seiner Zeit (Idealismus, Neukantianismus, Lebensphilosophie, Positivismus und vorrangig: Phänomenologie) stellt Adorno seine zentrale Frage, nämlich »ob nach dem Scheitern der letzten großen Anstrengungen überhaupt noch eine Angemessenheit zwischen den philosophischen Fragen und der Möglichkeit ihrer Beantwortung besteht: ob nicht vielmehr das eigentliche Ergebnis der jüngsten Problemgeschichte die prinzipielle Unbeantwortbarkeit der philosophischen Kardinalfragen sei« (ebd.). Er gibt weder eine positive noch eine negative Antwort auf diese Frage. Seine Strategie ist es vielmehr, diese Frage selbst zu einem relevanten Thema der Philosophie zu erheben. Philosophiekritik sei die wesentliche Aufgabe der Philosophie. Für ihn besteht diese Aufgabe vorrangig darin, den Totalitätsbegriff der Philosophie zu kritisieren. Die Philosophie müsse lernen, »auf die Totalitätsfrage zu verzichten « (ebd.: 336). ${ }^{177}$ Adorno transponiert den marxistisch-geschichtsphilosophischen Gedankengang, wonach sich die Philosophie im Namen gesellschaftlicher Veränderungen aufzulösen habe, also in den Bereich der Philosophie: Er konfiguriert die Denkfigur der gegenseitigen Durchdringung von Praxis und Theorie als ein zentrales und neues Problem für die Philosophie selbst und nicht, wie Lukács und Korsch, als ein affirmativ verstandenes Ziel, um gesellschaftliche Veränderung zu erreichen.

Die Frage nach der Auflösung der Philosophie, so bekräftigt Adorno, sei keineswegs »rhetorisch« gemeint, sondern »buchstäblich« zu nehmen, denn

177 In diesem Aspekt decken sich die Bemühungen von Adorno mit jenen von Michel Foucault: »Was bedeutet heute eigentlich >philosophieren<? Es bedeutet nicht die Konstituierung eines Diskurses über die Totalität, eines Diskurses, in dem die Totalität der Welt eingefangen ist, sondern eher die Ausübung einer bestimmten Tätigkeit« (Foucault 1974: 18). Die salte Philosophie`, so sagt Foucault in ähnlicher Weise wie Horkheimer und Adorno, habe darin bestanden, die Totalität der Welt einzufangen. Die >neue $\triangleleft$ die gegenwärtige Philosophie jedoch bestehe in einer Tätigkeit. »Wenn die Philosophie also nicht mehr so sehr ein bestimmter Diskurs, als vielmehr eine einem objektiven Feld immanente Tätigkeit ist, kann sie nicht mehr eine totalisierende Perspektive beanspruchen« (ebd.). 
»jede Philosophie, der es heute nicht auf Sicherheit des bestehenden geistigen und gesellschaftlichen Zustandes, sondern auf Wahrheit ankommt, sieht sich dem Problem einer Liquidation der Philosophie selber gegenüber « (ebd.). Diese Aussage erinnert an Korschs Vehemenz, mit der er die Auflösung der Philosophie als ein zentrales Moment marxistischer Theorie artikuliert. ${ }^{178}$ Sie ist hier in mehrfacher Hinsicht bedeutungsvoll: Eine Philosophie, der es auf Wahrheit ankomme, so mahnt Adorno, weiß um deren potenzielle Auflösung. Die Wahrheit der Philosophie liegt für ihn also darin, dass die Wahrheit nie gefunden werden kann. Er macht ein Paradox produktiv, das seine gesamte Philosophie durchzieht: dass Wahrheit zwar nie gefunden, aber dennoch immerwährend angestrebt werden muss. Es bleibe »das große, vielleicht das immerwährende Paradoxon: daß Philosophie stets und stets und mit dem Anspruch auf Wahrheit deutend verfahren muß, ohne jemals einen gewissen Schlüssel der Deutung zu besitzen; daß ihr mehr nicht gegeben sind als flüchtige, verschwindende Hinweise in den Rätselfiguren des Seienden und ihren wunderlichen Verschlingungen« (ebd.: 334). Adorno formuliert also in aller Deutlichkeit einen finalen Wahrheitsanspruch der Philosophie: dieser liegt darin, dass es philosophische Wahrheit in einer absoluten Version nicht gibt.

Seine Ambivalenz in Bezug auf die Frage, ob es philosophische Wahrheit gibt oder nicht, wurde in Bezug auf seinen berühmten Satz »Das Ganze ist das Unwahre « mehrfach kritisiert. ${ }^{179}$ Diese Ambivalenz ist in der hier eingenommenen Perspektive nun aber ein produktives Element innerhalb seines Erneuerungsanspruchs:

So genau ich mir der Unmöglichkeit bewußt bin, das Programm auszuführen, das ich Ihnen gab - einer Unmöglichkeit, die nicht bloß von der Enge der Stunde

${ }_{178}$ Siehe das Unterkapitel »Aufhebung der Philosophie: Durchdringung von Theorie und Praxis« (S. 152-155).

179 Es sei unverkennbar, betont etwa Demirović, »dass Adornos Argumentation tendenziell eine privilegierte Erkenntnisposition ausweist. [...]. >Das Ganze ist das Unwahre $<$ - und gegen diese über den vorfindlichen Bewusstseinsstand hinausreichende Erkenntnis gibt es kein Vetorecht. [...] Denn jede andere Theorie, die weder das Ganze umfängt noch in ähnlicher Weise verurteilt, ist lediglich ein Bestandteil des Unwahren und verhält sich nur apologetisch-affirmativ zu diesem Ganzen« (Demirović 1999: 533). Wie Demirović in der Folge ausführt, warnt Adorno jedoch vor genau dieser privilegierten Erkenntnisposition: »Er [Adorno, MD] spricht als Dialektiker über das System spätkapitalistischer Gesellschaft; doch gleichzeitig warnt er davor, diese Rede als Ausgangspunkt der Besserwisserei zu stilisieren « (ebd.: 535). In der hier eingenommenen Perspektive ist es genau diese Ambivalenz zwischen der Behauptung eines absoluten Wahrheitsanspruchs und der gleichzeitigen Ablehnung desselben, die für die Aktualisierung der Kritischen Theorie als Philosophie konstitutiv ist. 
herrührt, sondern generell besteht, weil gerade als Programm, in Vollständigkeit und Allgemeinheit dies Programm sich nicht ausführen läßt - : so deutlich sehe ich die Verpflichtung, Ihnen einige Hinweise zu geben. (ebd.: 339)

Adorno betont das Paradox, dass ein in sich geschlossenes philosophisches Programm zwar unmöglich ist, dass er aber als antretender Professor der Philosophie verpflichtet ist, ein solches anzustreben. Gerade indem er die Unmöglichkeit eines in sich geschlossenen philosophischen Systems reflektiert, legitimiert er sein eigenes neues philosophisches Programm als $\gg$ Deutung ${ }{ }^{180}{ }^{10}$ Er argumentiert hier doppelgleisig: Auf der einen Seite tritt er mit dem expliziten Anspruch auf, die Philosophie und mit ihr abschließende philosophische Systeme in ihren Grundfesten zu kritisieren. Auf der anderen Seite jedoch argumentiert er, dass in genau diesem Anspruch die neue und zukunftsweisende Philosophie liegt.

Nach diesem Auftakt, in dem Adorno sein Unbehagen ausdrückt, ein eigenes Programm überhaupt vorzustellen, stellt er es in seiner Antrittsrede dennoch vor: Erstens, so formuliert er, kämen seine eigenen Postulate einer »Liquidation« der Philosophie äußerst ähnlich. Die »Idee philosophischer Deutung weicht nicht vor jener Liquidation der Philosophie zurück, die mir durch den Zusammenbruch der letzten philosophischen Totalitätsansprüche signalisiert scheint « (ebd.: 339). Sein eigenes Programm bestehe folglich in der Kritik an der Philosophie selbst: »Da das philosophische Denken der Gegenwart, jedenfalls das offizielle, bislang diese Forderungen von sich fernhält oder allenfalls einzelne gemildert sich zu assimilieren trachtet, so scheint eine der ersten und aktuellsten Aufgaben die radikale Kritik des herrschenden philosophischen Denkens« (ebd.: 339). Sein Programm zielt also erstens auf die Auflösung des Totalitätsbegriffs in der Philosophie. Es zielt zweitens auf eine Kooperation mit den Sozialwissenschaften und der Soziologie. Eine wirkliche Veränderung des philosophischen Bewusstseins, so Adorno, setze sich nur in »strengster dialektischer Kommunikation mit den jüngsten Lösungsversuchen der Philosophie« durch. Diese Kommunikation wiederum werde »ihr einzelwissenschaftliches Material vorwiegend der Soziologie zu entnehmen haben [...]« (ebd.: 340). Werden beide von Adorno fokussierten Punkte zusammengezogen, ergibt sich folgendes Bild: Um den Totalitätsbegriff in der Philosophie und damit >die Philosophie< kritisieren zu können, ist diese >neue< Philosophie auf »einzelwissenschaftliches Material« aus der Soziologie angewiesen.

180 Adorno betont an anderer Stelle, dass sein Ansatz der Hermeneutik dem von Dilthey zwar nahekommt, um aber sogleich klarzustellen, dass er mit diesem inkommensurabel sei (Adorno 2001: 182-184). 
Mithilfe der Soziologie - so die Implikation - wird Philosophie ihrer Unmöglichkeit zum Trotz wieder möglich.

Adorno rekurriert in seiner Antrittsvorlesung, genau wie Lukács und Korsch, auf die Methode von Marx. Er bezieht sein eigenes philosophisches Programm der »Deutung « sowohl auf den »Materialismus « als auch auf die »Dialektik« (ebd.: 336-339). Seine Formulierungen jedoch sind zurückhaltend: »Ich möchte hier keine materialen Behauptungen aufstellen, sondern allein die Richtung anzeigen, in welcher ich die Aufgaben philosophischer Deutung erblicke« (ebd.: 337). Im Unterschied zu Lukács und Korsch, die wie gezeigt - die Philosophie für die marxistische Theorie produktiv machen, macht Adorno marxistische Theorieelemente für die Philosophie produktiv. Eine Stelle, in der er sich ausdrücklich auf Lukács beruft, illustriert diesen Vorgang in prägnanter Weise: »Würde Philosophie heute [...] nach dem Sinn von Sein schlechtweg [fragen] - sie bliebe entweder in formaler Unverbindlichkeit stehen oder spaltete sich in eine Vielheit möglicher und beliebiger weltanschaulicher Standpunkte« (ebd.: 337). Er grenzt sich hier von der philosophischen Frage nach dem »Sein schlechtweg« ab - ein Seitenhieb gegen Heidegger -, um sogleich eine mögliche Lösung zu präsentieren, wie die Frage dennoch gestellt werden könnte: »ich gebe gedankenexperimentell ein Beispiel, ohne dessen tatsächliche Durchführbarkeit zu behaupten« (ebd.). Die Lösung liege im Rückbezug auf die Figur der »Warenform «. Damit wäre zwar nicht das Ding-an-sich-Problem gelöst, »auch nicht in der Weise, dass etwa die gesellschaftlichen Bedingungen aufgewiesen wären, unter denen das Ding an sich-Problem zustande kommt, wie noch Lukács die Lösung dachte; denn der Wahrheitsgehalt eines Problems ist von den historischen und psychologischen Bedingungen, aus welchen es erwächst, prinzipiell verschieden« (ebd.: 337). Es bestehe dadurch jedoch die Möglichkeit, dass das Ding-an-sich-Problem verschwinden würde: »dass die geschichtliche Figur der Ware und des Tauschwertes gleich einer Lichtquelle die Gestalt einer Wirklichkeit freilegte, um deren Hintersinn die Erforschung des Ding an sich-Problems vergebens sich mühte, weil sie keinen Hintersinn hat, der von ihrem einmaligen und erstmaligen geschichtlichen Erscheinen ablösbar wäre« (ebd.: 337). Adornos Andeutung, mit dem Rückbezug auf die »Figur der Warenform « das Ding-ansich-Problem zum Verschwinden zu bringen, ist bezeichnend: Ein Interesse und Anliegen von ihm liegt, so wird deutlich, im Fortschritt der Philosophie, und zwar im Sinne der Lösung traditioneller philosophischer Probleme. Die Theorieelemente des Marxismus - vorrangig der Aspekt der Auflösung der Philosophie - dienen hierfür als argumentative Instrumente.

Die Paradoxie, die Adorno und auch Horkheimer für ihr eigenes Programm produktiv machen, wird deutlich: Auf der einen Seite wird die Kritik an 
der Philosophie als eine der zentralsten Aufgaben der sneuen< Philosophie definiert. Auf der anderen Seite jedoch wird - mit Zuhilfenahme der Sozialwissenschaften und der Soziologie - dieses neue Programm dezidiert mit der philosophischen Tradition gerechtfertigt und argumentativ in diese eingefügt.

\section{Die Genese der Kritik aus der Philosophie selbst}

In seinem 1962 publiziertem Aufsatz »Wozu noch Philosophie?« macht Adorno besonders deutlich, dass der Erneuerungsanspruch der Philosophie als Kritische Theorie mit einem Rückbezug auf die Tradition der Philosophie selbst begründet wird. Er extrahiert hier Theorieelemente aus der traditionellen Philosophie, um seine Definition der Philosophie als Kritik herzuleiten: »Kants berühmtes Diktum, der kritische Weg sei allein noch offen, gehört zu jenen Sätzen, an denen die Philosophie, aus der sie stammen, sich bewährt, indem sie, als Bruchstücke, das System überdauern« (Adorno 1977 [1962]: 461). Dass die Kritik ein wesentliches Element der Philosophie ist, begründet Adorno aber nicht nur mit Kant, sondern mit den Anfängen der Philosophie selbst: »Die überlieferten Philosophen dagegen waren, seit den gepriesenen Vorsokratikern, Kritiker « (ebd.: 462). Die Philosophien von Xenophanes, Platon, Descartes, Kant, Hegel oder Marx resultierten je aus Kritik und nicht aus der Übernahme von Thesen. »Jene Denker hatten in Kritik die eigene Wahrheit. Sie allein, als Einheit des Problems und der Argumente, nicht die Übernahme von Thesen, hat gestiftet, was als produktive Einheit der Geschichte der Philosophie gelten mag « (ebd.).

Adorno begründet seine Aktualisierung der Philosophie als Kritik folglich mit dem philosophischen Kanon. ${ }^{181}$ Auffällig in diesem Zusammenhang ist, dass er zwar die abendländische philosophische Tradition in affirmativer Weise als eine Reihe von Kritiken darstellt, zwei seiner Zeitgenossen - Carnap und Heidegger - jedoch nicht in diese Reihe aufnimmt. Er bezeichnet sowohl den Positivismus von Carnap als auch die Ontologie von Heidegger als »Heteronomien «, die es zu kritisieren gelte. »Ist Philosophie noch nötig«, schreibt er, »dann wie von je als Kritik, als Widerstand gegen die sich ausbreitende Heteronomie $[. .$.$] 《 (ebd.: 464). Adorno spricht dadurch sowohl der Philosophie$ Heideggers als auch der Carnaps die Möglichkeit von Kritik ab.

181 Dieser Aspekt ist bei Adorno besonders ausgeprägt: Sein Werk, so der hier gewonnene Eindruck, ist eine einzige Beschäftigung mit der Philosophie. Zu seiner Beschäftigung mit Husserl siehe z.B. Adorno 1972a; Adorno 2002. Insbesondere mit Heidegger hat sich Adorno intensiv auseinandergesetzt, z.B. Adorno 1972c; Adorno 2002. 
In der Passage hingegen, in der Adorno entgegen seiner vorherigen positiv gefärbten Darstellung die abendländische Philosophie in negativer Weise als eine »trostlose Kette« beschreibt, fügt er Carnap und Heidegger indirekt hinzu.

\begin{abstract}
Sind aber die beiden Heteronomien [Positivismus und Ontologie] die Unwahrheit und läßt diese zwingend sich demonstrieren, dann fügt das nicht nur der trostlosen Kette der Philosophien eine neue hinzu, sondern meldet auch eine Spur von Hoffnung an, Unfreiheit und Unterdrückung, das Übel, das so wenig eines philosophischen Beweises bedarf, daß es das Übel sei, wie daß es existiert, möchte doch nicht das letzte Wort behalten. (ebd.: 465)
\end{abstract}

Adorno kritisiert zwei wirkmächtige zeitgenössische philosophische Positionen als unfrei und unterdrückend, indem er seine eigene Methode auf sie anwendet. Dadurch stützt er den Wahrheitsgehalt seiner eigenen Methodik: Wenn durch ein kritisches Verfahren deutlich gemacht werden könne, dass Ontologie und Positivismus unwahr sind, gebe es die Hoffnung auf die Möglichkeit, Wahrheit von Unwahrheit trennen zu können.

Der erste Absatz aus dem Aufsatz »Wozu noch Philosophie?« ist in Bezug auf Adornos eigene Positionierung als Philosoph aufschlussreich. Er stellt im ersten Satz klar, dass er den »amateurhaften Klang « der Frage »Wozu noch Philosophie? « nicht überhöre, obwohl er selbst für diese Formulierung verantwortlich sei. Der allvertraute Ablauf, der meistens auf diese Frage folge-»ein[] Gedankengang, der alle möglichenSchwierigkeiten und Bedenken anhäuft, um schließlich mehr oder minder vorsichtig, in ein Jedennoch zu münden und das rhetorisch Bezweifelte zu bejahen « -, entspreche einer »konformistischen und apologetischen Haltung « (Adorno 1977 [1962]: 459). Diese Haltung wiederum hängt für Adorno mit der »bürgerlichen Existenz« desjenigen zusammen, der von »Amts wegen Philosophie lehrt« und der die »eigenen handgreiflichen Interessen verletzt, sobald er sich dagegen äußert« (ebd.). Adorno legt - es zeigt sich auch an vielen anderen Textstellen - einen zentralen Aspekt von Seidels Circulus vitiosus analytisch klar. Er macht Paradoxien und Widersprüche sichtbar und lässt Fragen offen. Die Frage, wie die eigene Denk- und Sprechposition legitimiert werden kann, wenn diese Position lediglich ein Ausdruck einer privilegierten sozialen und historischen Situation (hier der bürgerlichen Existenz) ist, wird von Adorno zwar nicht abschließend beantwortet, aber als philosophisch relevant ausgewiesen. Ähnlich wie es bei Schlick und seinem Aufsatz »Die Wende der Philosophie« deutlich geworden ist, ${ }^{182}$ nimmt Adorno gleich zu Beginn den möglichen Einwand vorweg, dass die Frage, die er stellt, im Grunde eine traditionelle philosophische Frage sei,

182 Siehe das Unterkapitel »Eine grundsätzliche Wende der Philosophie« (S. 92-95). 
mit deren Beantwortung sich bürgerliche Philosophen ihre eigene Existenzberechtigung sichern wollten. Dass er - Adorno - dennoch ein Recht habe, diese Frage zu stellen, begründet er damit, dass er sich der Antwort auf die Frage nicht sicher sei. »Einiges Recht, trotzdem die Frage aufzuwerfen, habe ich bloß deshalb, weil ich der Antwort keineswegs gewiss bin« (ebd.). Er begründet sein Sprechen hier also gewissermaßen mit der sokratischen Figur des Nichtwissens: Er erklärt sein »Recht«, sich in den traditionellen philosophischen (bürgerlichen) Diskurs einzuschreiben, mit der Bemerkung, dass ihm bewusst sei, dass dieser Vorgang paradox ist. Er legitimiert seine eigene Position mit einer Reflexion auf die eigene Aussage.

Adorno verfolgt also eine ähnliche Strategie, wie sie weiter oben in Bezug auf das ausgestellte Unbehagen bezüglich der eigenen Programmatik deutlich geworden ist: Die Reflexion der eigenen Sprechposition und eine ausgestellte Unsicherheit werden als Begründung eingesetzt, sich dennoch mit traditionellen Fragen auseinanderzusetzen. Adorno stellt sich selbst in die Reihe all jener traditionellen Philosophen, die sich mit dem Sinn und Zweck von Philosophie auseinandersetzen, um sich gleichzeitig von ihnen zu distanzieren: Der Gegensatz, den Adorno zwischen seiner eigenen Position und denjenigen anderer Philosophen eröffnet, liegt im Argument, dass er sich - im Unterschied zu anderen Philosophen - bewusst sei, dass er seiner Antwort nicht gewiss ist.

In der Folge argumentiert er - auch hier gleichen seine Strategien denjenigen im Wiener Kreis -, dass Philosophie, wenn sie sich als System versteht, immer widersprüchlich ist. »Philosophie, die sich noch als total, als System aufwürfe, würde zum Wahnsystem« (ebd.: 461). Er diskutiert diesen Aspekt im Zusammenhang mit dem Positivismus Carnap'scher Prägung, der Ontologie Heideggers und der Dialektik in Anlehnung an Marx. Er formuliert ein der Philosophie inhärentes Problem: »Gibt sie [die Philosophie, MD] jedoch den Anspruch der Totalität auf; beansprucht sie nicht länger mehr, aus sich heraus das Ganze zu entfalten, das die Wahrheit sein soll, so gerät sie in Konflikt mit ihrer ganzen Überlieferung« (ebd.). Hier wird ein signifikanter Unterschied zum Wiener Kreis deutlich: Wo die Vertreter des Wiener Kreises aus der Einsicht, dass der Philosophie ein Totalitätsdenken inhärent ist, die philosophische Tradition toto genere ablehnen, beleuchtet Adorno diesen Aspekt genauer: Er macht die Kritik am Absolutheitsanspruch, welcher der Philosophie inhärent ist, zur Grundlage seines eigenen Erneuerungsanspruchs: Philosophie, wie sie angesichts des Unsäglichen, was geschah und weiter geschehen kann, allein zu verantworten wäre, dürfte nicht länger des Absoluten sich mächtig dünken, ja müsste den Gedanken daran sich verbieten, um ihn nicht zu verraten, und doch vom emphatischen Begriff der Wahrheit nichts sich abmarkten lassen. 
Dieser Widerspruch ist ihr Element. Es bestimmt sie als negative« (ebd.). Die einzig noch mögliche Philosophie, so lässt sich Adorno verstehen, müsse den Anspruch nach dem Absoluten aufgeben, gerade weil ihr dieses Absolute inhärent ist - und inhärent sein soll. Genau dieser Widerspruch wiederum definiere die Philosophie, wie sie einzig noch legitim ist: als Kritik.

In diesem Verfahren eingeschlossen ist zugleich eine bestimmte Form der Selbstkritik: »Zum Begriff der Philosophie gehört auch die Reflexion auf die Stellung der Philosophie in der Wirklichkeit ihrer geschichtlichen Stunde« (Sommer 2016: 24). Wie Marc Sommer schreibt, sei darin auch eine »Absetzung von der philosophischen Tradition impliziert, insofern diese es gewöhnlich verschmäht hat [...] auf ihre Stellung in und zur gesellschaftlich-geschichtlichen Wirklichkeit zu reflektieren«(ebd.). Adorno, so wird deutlich, reaktualisiert ein Philosophieverständnis, in dem die Philosophie auf sich selbst reflektiert. »Die von Adorno anvisierte Selbstreflexion impliziert damit auch eine Reflexion auf das Maß, in dem die Philosophie bis in ihr Innerstes von ihrer geschichtlichen Wirklichkeit affiziert wird « (ebd.). Wie bereits deutlich geworden ist, wendet er diesen Begriff von Philosophie auf zwei zeitgenössisch wirkmächtige philosophische Traditionen an: auf die Ontologie einerseits, auf den Positivismus andererseits.

\section{"Kein dritter Standpunkt" - eine Methode}

»Philosophische Kritik heute«, sagt Adorno in »Wozu noch Philosophie?«, sei »mit zwei Schulen konfrontiert, die als Geist der Zeit, gewollt oder ungewollt, übers akademische Gehege hinaus wirken « (Adorno 1977 [1962]: 462). Die eine sei der vom »Wiener Kreis inaugurierte logische Positivismus«, die andere bestehe in den »ontologischen Richtungen « (ebd.). Beide Schulen, so Adorno ausdrücklich, »divergieren und sind gleichwohl komplementär« (ebd.). »Positivismus und Ontologie sind einander anathema; jener hat durch einen seiner Hauptexponenten, Rudolf Carnap, die Theorie Heideggers, und zwar zu Unrecht, als sinnleer attackiert. Umgekehrt heißt das positivistische Denken den Ontologen Heideggerscher Provenienz seinsvergessen; es profaniere die eigentliche Frage « (ebd.: 463). ${ }^{183}$ Sowohl der Ontologe Heidegger als auch der Positivist Carnap verfehlen laut Adorno das primäre Ziel von Philosophie: »Sie haben Metaphysik als gemeinsamen Feind erkoren« (ebd.). Eine Folge dieser »gemeinsamen Aversion gegen Metaphysik« sei der Verlust des Denkens:

183 Adorno spielt hier vermutlich auf die Debatte zwischen Carnap und Heidegger an, die Heideggers 1929 erschienener Aufsatz »Was ist Metaphysik? lanciert hatte. Siehe dazu das Kapitel »Philosophische Altlasten aus dem Weg räumen: Metaphysikkritik« (S. 100-105). 
»Denken wird beiden Richtungen zum notwendigen Übel, tendenziell diskreditiert. Es verliert das Moment von Selbstständigkeit. Die Autonomie der Vernunft entschwindet [...]« (ebd.: 464).

Adorno wirft Heidegger und Carnap also gewissermaßen in einen gemeinsamen Topf. Deren Kampf gegen die Metaphysik sei der falsche Weg. Es gehe um Wichtigeres: um die Unabhängigkeit des Denkens. ${ }^{184}$ Hier begegnet die Argumentationsstrategie, die vor allem bei Husserl, aber auch im Wiener Kreis sichtbar geworden ist, erneut: Indem Adorno zwei Denkströmungen seiner Zeit als in sich verfahren darstellt, bringt er seinen eigenen Zugang als jene Philosophie hervor, die einen Ausweg aus dieser verfahrenen Situation weisen kann. »Dialektik ist kein dritter Standpunkt[,] sondern der Versuch, durch immanente Kritik philosophische Standpunkte über sich und über die Willkür des Standpunktdenkens hinauszubringen « (ebd.: 467). Dass seine eigene Methode sich auf keinen Standpunkt bezieht, schreibt er auch zu Beginn der Negativen Dialektik: »Dialektik ist das konsequente Bewußtsein von Nichtidentität. Sie bezieht sich auf keinen Standpunkt« (Adorno 1966: 15). Den möglichen Vorwurf, dass der Dialektik »ihrerseits alles, was in ihre Mühle gerät, auf die bloß logische Form des Widerspruchs « hinauslaufe, weist er mit dem Argument zurück, dass man dadurch »die Schuld der Sache auf die Methoden« schiebe (ebd.).

Adorno formuliert explizit, worauf es in der hier eingenommenen Perspektive ankommt: Die Privilegierung der eigenen Zugangsweise wird dadurch begründet, dass die eigene Methode als standpunktlos vorgestellt und verteidigt wird. Mit dem Verfahren der immanenten Kritik könnten, so Adorno, die Unwahrheit von Ontologie und Positivismus aufgezeigt werden. Umgekehrt wiederum bestärkt dies den Wahrheitsgehalt der immanenten Kritik. Dass es sich dabei um eine Methode - und nicht etwa um ein philosophisches System - handelt, ist zentral: Wie es auch die Beispiele Husserl und Wiener Kreis nahelegen, werden philosophische Erneuerungen im 20. Jahrhundert durch die Entwicklung und Erhärtung von neuen Methoden und deren Anwendung auf andere Philosophien legitimiert. Gerade indem Adorno dezidiert betont und argumentiert, dass Dialektik sich - im Gegensatz zu den anderen Philosophien - auf keinen Standpunkt bezieht und so zumindest potenziell der Verdinglichung entkommen kann, bringt er sein eigenes Philosophieverständnis als einzige legitime Form von Philosophie hervor.

184 Diese Argumentationsstrategie ließe sich auch an Horkheimers Aufsatz »Der neueste Angriff auf die Metaphysik« (1937) zeigen. Horkheimer schließt seine scharfe Kritik am Wiener Kreis mit dem ironischen Satz: »Auf den neuesten Angriff darf die Metaphysik stolz sein; sie wird mit dem Denken verwechselt« (Horkheimer 1988 [1937]: 161). 


\section{Wahrheit statt Opferung des Geistes}

Die Wahrheit und damit letztlich auch die Philosophie, die Adorno verteidigt, ist - wie er 1965 in seiner Vorlesung »Zur Lehre von der Geschichte und von der Freiheit« formuliert - im Einzelnen lokalisiert: »Und das eben verweist die Erkenntnis des Einzelnen als eine philosophische Erkenntnis auf das einzige, was einem solchen Einzelnen und Zerstreuten gegenüber bleibt, - nämlich auf seine Interpretation, auf die Kunst seiner Deutung (Adorno 20o1: 184). Die im Einzelnen und Singulären überdauerte Wahrheit wiederum werde durch Kritik überliefert: »Im Fortgang solcher Kritik haben auch diejenigen Philosophien ihren Zeitkern, ihren geschichtlichen Stellenwert gewonnen, deren Lehrgehalt auf dem Ewigen und Zeitlosen beharrte « (Adorno 1977 [1962]: 459). Die Idee der Zeitlosigkeit der Wahrheit wird dadurch umgedeutet in die Idee der Wahrheit als Zeitkern. Adorno übernimmt diesen Begriff von Walter Benjamin. Dieser schreibt: »Entschiedene Abkehr vom Begriffe der >zeitlosen Wahrheit< ist am Platz. Doch die Wahrheit ist nicht - wie der Marxismus behauptet - nur eine zeitliche Funktion des Erkennens, sondern an einen Zeitkern, welcher im Erkannten und Erkennenden zugleich steckt, gebunden. Das ist so wahr, daß das Ewige jedenfalls eher eine Rüsche am Kleid ist als eine Idee (Benjamin 1982: 578$).{ }^{185}$

Adornos argumentative Reaktivierung einer traditionellen Vorstellung von Philosophie - die Philosophie als unabhängige Instanz des Denkens, die Wahrheit von Unwahrheit scheiden kann - scheint ein bewusster Akt gewesen zu sein. Er benennt sein eigenes Verhältnis zur Philosophie zu Beginn des Textes »Wozu noch Philosophie?« als »ungünstig «, »anachronistisch« und als »fatalistisch «. »Wer eine Sache verteidigt, die der Geist des Zeitalters als veraltet und überflüssig abtut, begibt sich in die ungünstigste Position. Seine Argumente klingen schwächlich beflissen. [...] Diese Fatalität muss einbeziehen, wer von der Philosophie nicht sich abbringen lässt« (ebd.: 459). Adorno positioniert, so ist deutlich geworden, seinen Anspruch auf eine selbstkritische Philosophie als eine neue Form von Philosophie und reiht diese in die philosophische Tradition ein. »Weil Philosophie zu nichts gut ist, ist sie noch nicht verjährt; und selbst darauf dürfte sie sich nicht berufen, wenn sie nicht ihre Schuld, die Selbstsetzung, verblendet wiederholen will« (ebd.: 471). Gerade

185 »Was die Bilder von den >Wesenheiten< der Phänomenologie unterscheidet, das ist ihr historischer Index. (Heidegger versucht vergeblich die Geschichte für die Phänomenologie abstrakt, durch die >Geschichtlichkeit< zu retten.) Diese Bilder sind durchaus abzugrenzen von den >geisteswissenschaftlichen $<$ Kategorien, dem sogenannten Habitus, dem Stil etc. Der historische Index der Bilder sagt nämlich nicht nur, daß sie einer bestimmten Zeit angehören, er sagt vor allem, daß sie erst in einer bestimmten Zeit zur Lesbarkeit kommen« (Benjamin 1982: 577). 
weil Adorno betont, dass diese »Schuld «, die der philosophiae perennis, d.h. der Idee ewiger Wahrheit, überliefert werde, nicht wiederholt werden dürfe (ebd.), aktualisiert er die Philosophie als ein Gebiet, das verteidigt werden muss. Er schlägt letztlich »die Treue zur Philosophie, das Festhalten des philosophischen Impulses trotz des Endes des Systems « vor (Adorno 2001: 183-184), denn dass die Philosophie als System nicht mehr möglich sei, bedeute nicht, dass sie »den Geist opfern soll« (ebd.: 184).

\subsection{Selbstreflexion als philosophisches Programm}

Die neue und zugleich alte, sich selbst reflektierende Philosophie wird von Adorno als eine Art Rettung beschrieben: Ohne die Unabhängigkeit des Denkens, also ohne eine sich selbst reflektierende Philosophie, würde die Menschheit den unberechenbaren Sachzwängen gesellschaftlicher Entwicklung überlassen werden. Das Moment der Krise, das vor allem am Beispiel von Husserl deutlich geworden ist, tritt auch hier hervor: Die Philosophie - in Form der Unabhängigkeit des Denkens - wird als eine Form des Widerstandes in einer in der Krise steckenden Welt dargestellt. Gerade indem Horkheimer und Adorno den Verblendungszusammenhang der Philosophie dezidiert offenlegen, evozieren sie Möglichkeiten, wie Philosophie - ihrer Unmöglichkeit zum Trotz - dennoch praktiziert werden kann: nämlich als sozialwissenschaftlich informierte Kritik. ${ }^{186}$ Gleichzeitig aktualisieren die Autoren die Relevanz der Philosophie als Gesellschaftskritik. ${ }^{187}$

Die philosophische Erneuerung durch die Kritische Theorie ist konstitutiv mit der philosophischen Erneuerung des Marxismus in den 1920er-Jahren verknüpft. Sie erzielt ihre Wirkung wesentlich durch einen spezifischen Umgang

186 Dass Horkheimer und Adorno die Kritische Theorie als eine neue, sozialwissenschaftlich ausgerichtete Philosophie institutionalisierten und dass dies in einem Spannungsverhältnis zu ihrem marxistisch geprägten philosophiekritischen Anspruch stand, beschreibt Friederich O. Wolf 1972: »Das >Absterben der Philosophie< und ihre >Aufhebung ¿ durch die >kritische Theorie der Gesellschaft< erschienen zunächst als ebenso sinnfällige wie theoretisch wohlbegründete Tatsachen, daß es sich die Mühe nur unter besonderen Umständen lohnt, die Philosophie als faktisch noch existierende akademische Disziplin zu kritisieren« (Wolf 1972: 31).

187 In ihrer Studie Zum Verhältnis von Gesellschaftstheorie und Erkenntnistheorie. Untersuchungen zum Totalitätsbegriff in der kritischen Theorie Adornos argumentiert Christel Beier, dass Adornos Intention, Gesellschaftstheorie philosophisch zu begründen, die Ebene einer wissenschaftlichen Thematisierung von Gesellschaft systematisch verfehle (Beier 1977). 
mit dem Totalitätsbegriff: ${ }^{188}$ Die Gesellschaft wird von Adorno in Anlehnung an Lukács als ein »totales Gefüge« bestimmt, das potenziell erfasst werden könne. ${ }^{189}$ Obwohl Adorno dazu aufruft, die Philosophie müsse lernen, auf die Totalitätsfrage zu verzichten, verzichten er und Horkheimer selbst nicht auf das Konzept der Totalität. Der Verzicht besteht vielmehr im Anspruch, diese Totalität vermittels der Philosophie (wie es der idealistisch-metaphysischen Philosophie unterstellt wird) oder vermittels eines Klassenstandpunktes (wie es dem Marxismus unterstellt wird) erfassen zu können. Dadurch wird eine Umkehrung der Funktion der traditionellen Philosophie möglich. Die >traditionelle< Aufgabe der Philosophie, nämlich die »Totalität der Wirklichkeit« erkennen zu können, wird umgedeutet in die `kritischeく Aufgabe der Philosophie, nämlich die »Totalität der Wirklichkeit« kritisieren zu können.

Auf der Basis des Scheiterns einer Verwirklichung der Philosophie in der Praxis rekonzeptualisieren dieVertreter der Kritischen Theorie die marxistische Philosophie durch eine Kooperation mit den empirischen Sozialwissenschaften als abstraktes Deutungsinstrument gesellschaftlicher Verhältnisse: »Dass die philosophische Arbeit eine abstrakte war und ist, gründet in den gesellschaftlichen Daseinsverhältnissen. Das Festhalten an der Abstraktheit in der Philosophie ist der Sachlage entsprechender und kommt der Wahrheit näher als jene pseudo-philosophische Konkretheit, die sich von oben zu den gesellschaftlichen Kämpfen herablässt« (Horkheimer/Marcuse 1970 [1937]: 640). Mit Rüdiger Dannemanns Einschätzung, dass Adornos Konzeption »sich in unüberbietbarer Weise [...] gegen eine Praxisorientierung « sperre (Dannemann 1987:146), wird ein zentraler Aspekt formuliert: In der Kritischen Theorie werden marxistische Theorieelemente aus den 192oer-Jahren adaptiert, um diese im Wissenschaftskontext der Bundesrepublik der 195oerbis 1970er-Jahre explizit in die Akademie zu implementieren.

Am Beispiel von Horkheimer und Adorno wird eine Selbstpositionierungsstrategie greifbar, die ihre Stärke wesentlich durch das Argument erhält, es handele sich bei der Philosophie um eine Methode und nicht um die

188 Insofern auch Heidegger in der Folge von Husserl als `Erneuerer der Philosophie gilt, ist in diesem Zusammenhang Lucien Goldmanns These, wonach sich Lukács' Totalitätsbegriff und Heideggers Seinsbegriff in vielen Aspekten überschneiden würden, bezeichnend: »Was Heidegger uns von der Kategorie des Seins sagt, stand bereits bei Lukács anläßlisch der Totalität« (Goldmann 1975: 127).

189 Adornos berühmte Definition lautet: »Mit Gesellschaft im prägnanten Sinn meint man eine Art Gefüge zwischen Menschen, in dem alles und alle von allen abhängen: in dem das Ganze sich erhält nur durch die Einheit der von sämtlichen Mitgliedern erfüllten Funktionen und in dem jedem Einzelnen grundsätzlich eine solche Funktion zufällt, während zugleich jeder Einzelne durch seine Zugehörigkeit zu dem totalen Gefüge in weitem Maße bestimmt wird« (Adorno 1956: 22). 
Verteidigung wissenschaftlicher Standpunkte. Es ist eine Strategie, die auch bei Husserl und den Vertretern des Wiener Kreises sichtbar geworden ist: Die eigene Positionierung wird durch die Anwendung einer neuen Methode auf andere Wissenschaften und Theorien erwirkt. Die Anwendungen in der Kritischen Theorie zielen weit expliziter als in den anderen Beispielen auf die Philosophie selbst. Wo Husserl und der Wiener Kreis ihre Neupositionierung wesentlich durch die Auseinandersetzungen mit anderen Wissenschaften entwickeln, wird die Neupositionierung der Kritischen Theorie vorrangig durch die kritische Auseinandersetzung mit der Philosophie, deren Tradition und vor allem mit zeitgenössischen Philosophien entwickelt. »Die Entwicklung der negativen Dialektik [...] vollzieht sich in Adornos Werk über eine Auseinandersetzung mit der Phänomenologie von Husserl und Heidegger« (Römer 2012: 67).

Durch Adornos und Horkheimers Aktualisierungsstrategien wird die Möglichkeit einer sich selbst reflektierenden Philosophie erneuert. »Kritische Theorie heißt demnach auch, dass die Theorie zur Selbstkritik in diesem grundsätzlichen Sinne fähig ist « (Thomä 20o6: 44). Wie gezeigt ist diese Forderung nach philosophischer Selbstkritik gleichzeitig eine Begründungsstrategie. An dieser Stelle wird der Unterschied zwischen Seidel (als einem in der Philosophie nicht kanonisierten Autor) und Adorno (als einem Erneuerer des philosophischen Kanons) signifikant: Wo Seidel seinen Standpunkt - wie oben gezeigt - im Zusammenhang mit anderen Disziplinen beständig selbst reflektiert, fordert Adorno eine sich selbst reflektierende Philosophie. Die Reflexion seines eigenen Standpunkts verbleibt dadurch einer philosophieinternen Logik verhaftet: Er schreibt sich selbst das Recht, als Philosoph zu sprechen, mit dem Argument zu, dass er seinen Standpunkt als Philosoph selbst reflektiere. Ungesagt bleibt, was eine solche Reflexion, würde sie disziplinenübergreifend betrieben, für Fragen aufwerfen würde. Etwa: Wer spricht von welcher Position über wen und warum? Wie W. Meier, der Verfasser des Vorworts der Neuauflage von Bewußtsein als Verhängnis in den 197oer-Jahren formuliert, könne dieses Problem »auf den so Fragenden zurückschlagen « (Meier 1979: o.S.). Wo dieses »Zurückschlagen« bei Seidel in aller Vehemenz zum Vorschein kommt, wird es von Horkheimer und Adorno philosophisch operationalisiert: Selbstreflexion und Philosophie werden miteinander verknüpft. Die Reflexion des eigenen Standpunkts erscheint bei Adorno somit als argumentative Strategie, Philosophie und philosophische Selbstkritik zu legitimieren, nicht aber als Möglichkeit, die Philosophie und deren Standpunkte selbst spiegeln zu können. (Dieser Aspekt wird im nachfolgenden Fazit noch detaillierter ausgeführt.) 
Die zu Beginn des Kapitels an Seidels Bewußtsein als Verhängnis nachgezeichnete Krise, nämlich der Verlust der Legitimität des philosophischen Standpunkts, wird von Horkheimer und Adorno also aufgenommen und produktiv gewendet. Indem sie, wie Thomä schreibt, die Fähigkeit der Selbstkritik für die Philosophie aktualisieren, reagieren sie auf die durch andere Wissenschaften (vorrangig Soziologie, Psychologie und Psychoanalyse) ausgelöste Bedrohung, die Philosophie könnte ihre Legitimität in gesellschaftlicher, aber auch wissenschaftlicher Hinsicht verlieren. Indem Horkheimer und Adorno die Kritik als jene einzige Funktion behaupten, in der Philosophie noch legitim sein kann, klammern sie die Möglichkeit aus, dass diese Setzung gespiegelt werden kann. Die Ausklammerung der Möglichkeit, ihren Standpunkt selbst infrage zu stellen, eröffnet paradoxerweise die Möglichkeit einer sich selbst reflektierenden Philosophie. In gänzlich unterschiedlicher Weise als Husserl und die Vertreter des Wiener Kreises aktualisieren dadurch auch Adorno und Horkheimer einen Machtanspruch der Philosophie: Der Philosophie kommt im Verhältnis zu den anderen Wissenschaften das Primat zu, auf sich selbst reflektieren zu können.

Mit der Kritischen Theorie, so kann abschließend festgehalten werden, wird Seidels Schlussfolgerung, nämlich dass das analytische Bewusstsein an seinem eigenen Geist - der Wahrheit - zugrunde geht (Seidel 1927: 205), für die Philosophie produktiv umgewendet:

Philosophie insistiert darauf, daß die Handlungen und Ziele der Menschen nicht das Produkt blinder Notwendigkeit sein müssen. Weder wissenschaftliche Begriffe noch die Form des gesellschaftlichen Lebens, weder die herrschende Denkweise noch herrschende Sitten sollten gewohnheitsmäßig übernommen und unkritisch praktiziert werden. Der Impuls der Philosophie richtet sich gegen bloße Tradition und Resignation in den entscheidenden Fragen der Existenz; sie hat die undankbare Aufgabe übernommen, das Licht des Bewußtseins selbst auf jene menschlichen Beziehungen und Reaktionsweisen fallen zu lassen, die so tief eingewurzelt sind, daß sie natürlich, unveränderlich und ewig scheinen. (Horkheimer 1988 [1940]: 336-337)

Wo für Seidel das Bewusstsein an der Wahrheit - sprich Philosophie - zugrunde geht, fordern es Horkheimer und Adorno als Licht zurück, das den Trug ewiger Wahrheiten - sprich Philosophien - erhellen kann.

\section{Exkurs: Wahrheit und Macht}

Der philosophische Erneuerungsanspruch, der in der Kritischen Theorie sichtbar wird, ist mit der Perspektive des vorliegenden Buches enger verbunden als die anderen beiden Beispiele. Wie die geschilderte Nähe von Seidel mit 
der Kritischen Theorie nahelegt, beschäftigen sich Horkheimer und Adorno weit intensiver als Husserl oder die Vertreter des Wiener Kreises mit der Legitimation der Philosophie und der Wissenschaft im Allgemeinen. Die Denkrichtung, die Adorno und Horkheimer einschlagen, nimmt ihren Anfang in einer Problematik, die von Seidel mit Verzweiflung artikuliert und in der Dialektik der Aufklärung ihre akademische Entsprechung gefunden hat: im Prozess der Aufklärung und in der Entwicklung der modernen Rationalität als Prozess eines fortschreitenden Verhängnisses. Wissenschaft und Philosophie stehen mit der Wahrheit nicht mehr in einer Reihe, sondern im Widerstreit.

Im Rückblick betrachtet ist die wissenschaftliche Disziplinierung, aus der das vorliegende Buch entstanden ist, als eine Reaktion darauf zu verstehen, dass der Vernunft, Rationalität, Wissenschaft, Theorie und Philosophie keine Garantie auf Wahrheit zugrunde liegen. Wahrheit - so wurde in Fächern wie Wissenschaftsforschung, Geschlechterforschung, Soziologie und allgemein in den Kulturwissenschaften gelehrt und gelernt - sei immer nur in Relationen, immer nur historisierend und nie unabhängig von Machtverhältnissen denkbar. Daraus folgt, dass auch der eigene Forschungsblick immer situiert, beschränkt, verkörpert und folglich perspektivisch ist. Dass der Seidel'sche Teufelskreis in diesem Buch eine so zentrale Rolle einnimmt, ist der Problematik geschuldet, die daraus folgt: Von welcher Position aus kann die Gegenwart erfasst werden, wenn das eigene Denken selbst nicht außerhalb dieser Gegenwart steht? Wie können Wahrheitsansprüche kritisiert werden, ohne dass dadurch der eigene Standpunkt zum Maßstab aller anderen Standpunkte erklärt wird?

Eine Möglichkeit, mit dieser Problematik umzugehen, ist, die Art und Weise, wie Wahrheiten produziert werden, selbst zum wissenschaftlichen Gegenstand zu erklären. Insbesondere Michel Foucault hat diese Aufgabe gewissermaßen zu einem neuen philosophischen Programm erhoben. ${ }^{190}$ Unabgeschlossen und im Sinne eines Ausblicks soll an dieser Stelle kurz darauf eingegangen werden. Erstens, weil Foucaults Perspektive für die in diesem Buch eingenommene Zugangsweise prägend ist, und zweitens, weil seine tentativen Analysen über die antike parrhesia es ermöglichen, aus einem weiteren Blickwinkel zu erfassen, dass die Philosophie engen disziplinären Grenzen unterliegt.

Seit Friedrich Nietzsche liege die Aufgabe der Philosophie, so konstatiert Foucault in ähnlicher Weise wie Horkheimer und Adorno, nicht mehr darin,

190 Analog zu den untersuchten Philosophen verficht auch Foucault eine Definition, was Philosophie heute ist und sein sollte. Sie sei »eine Askese, eine Übung seiner selber, im Denken« (Foucault 1989 [1984]). Es gehe darum, zu »wissen, in welchem Maße die Arbeit, seine eigene Geschichte zu denken, das Denken von dem lösen kann, was es im Stillen denkt, und inwieweit sie es ihm ermöglichen kann, anders zu denken« (ebd.). 
eine Wahrheit zu suchen, die für alle zu allen Zeiten gültig ist, sondern sie liege darin, die Gegenwart zu diagnostizieren (Foucault 1974: 12). Mit Immanuel Kants Definition der Aufklärung sieht Foucault den Beginn einer ganz spezifischen philosophischen Reflexion entstehen, nämlich das aktuelle Geschehen in eine Beziehung zur Geschichte zu setzen. ${ }^{191}$ Diese philosophische Reflexiondieses ethos, wie Foucault schreibt - sei eine »Grenzhaltung « (Foucault 2007 [1994]: 185), d.h. auch und vor allem: Wahrheit, Subjekt und Macht seien einander durchkreuzende und bedingende Aspekte, deren Beziehungen es zu untersuchen gelte. ${ }^{192}$ „Was sind denn zuletzt die Wahrheiten des Menschen?«, fragt Nietzsche, auf den sich Foucault bezieht, und antwortet: »Es sind die unwiderlegbaren Irrthümer des Menschen« (Nietzsche 2003 [1882/87]: 518). Die Wahrheit sei deshalb ein unwiderlegbarer Irrtum, sagt wiederum Foucault, »weil die Geschichte ihn so hartgesotten hat, dass er sich nicht mehr verändern lässt« (Foucault 2002 [1971]: 170). Um die Gegenwart - oder zumindest Teile davon - zu erfassen, gelte es, Wahrheiten im Kontext von Macht- und Herrschaftsverhältnissen zu verstehen und zu untersuchen. Dies wiederum sei eine Form von Kritik: »Kritik heißt herausfinden, auf welchen Erkenntnissen, Gewohnheiten und erworbenen, aber nicht reflektierten Denkweisen die akzeptierte Praxis beruht (Foucault 2005 [1981]:221). Foucault aktualisiert und rehabilitiert, ähnlich wie es an den anderen drei Beispielen dieser Arbeit deutlich geworden ist, mit dem Rückbezug auf die philosophische Tradition ein neues Philosophieverständnis. Auch an ihm könnte ein philosophischer Erneuerungsanspruch abgelesen werden, der in den hier vorgestellten Mustern bearbeitbar wäre. ${ }^{193}$ In diesem Erneuerungsanspruch werden philosophische

191 »Ich finde ihn [Kants Text Beantwortung der Frage: Was ist Aufklärung?, MD] [...] erstaunlich und interessant, weil sich dort ein Philosoph zum ersten Mal als Philosoph die Aufgabe stellt, nicht nur das System oder die metaphysischen Grundlagen wissenschaftlicher Erkenntnis, sondern ein historisches Geschehen zu analysieren, und noch dazu ein ganz aktuelles« (Foucault 2005 [1982]: 280). Mit Kant tauche also die Frage nach der Gegenwart als einem historischen Ereignis in der philosophischen Diskussion erstmals auf. »Die Philosophie als Erscheinungsort einer Gegenwart, die Philosophie als Fragen nach dem philosophischen Sinn der Gegenwart, zu der sie selbst gehört, die Philosophie als Befragung dieses swir<, dem der Philosoph zugehört und gegenüber welchem er sich verorten muss, das, scheint mir, zeichnet die Philosophie als Diskurs der Moderne, als Diskurs über die Moderne aus« (Foucault 2009 [2008]: 29).

192 Vladimir Gradev stellt hierzu fest, dass Foucaults Spätwerk darauf konzentriert sei, zu zeigen, dass es weder eine ursprüngliche noch eine universelle Wahrheit gebe, die in versteckter Weise in der okzidentalen Metaphysik zu finden wären, sondern dass die Wahrheit im Gegenteil ganz und gar eine die Machtverhältnisse durchquerende Kraft sei (Gradev 1994: 44).

193 Gemäß Andrea Hemminger gehe es Foucault um »die in die Krise geratene Subjektphilosophie« (Hemminger 2004: 137). Dieser Kommentar legt nahe, dass Foucault die Krise 
Erkenntnisse radikal historisiert, um genau dadurch Aussagen über die Gegenwart machen zu können. Wahrheit tritt hier, ähnlich wie in der Kritischen Theorie, nur kontextabhängig zutage. ${ }^{194}$

In seinen letzten Vorlesungen (Foucault 1996; 2009 [2008]; 2010 [2009]) thematisiert Foucault diesen Erneuerungsanspruch weit expliziter als in seinen früheren Schriften, indem er die antike Figur der parrhesia ${ }^{195}$ und damit zusammenhängend die antiken Kyniker untersucht. Die parrhesiastische Rede sei der Elite, also den freien und erwachsenen Männern, vorbehalten. »La position du parrésiaste ne peut être occupée que par l'homme adulte libre, membre de la Cité. En principe, les étrangers, les femmes et les esclaves ne peuvent pas dire la vérité« (Gradev 1994: 45). Wahrheitsproduktionen, so folgt daraus, sind an die soziale Situation von Personen gebunden, also kontextbezogen. »Fremde«, »Frauen« und »Sklaven« sind in der antiken Philosophie nicht in den Bereich eingeschlossen, in dem Wahrheit gesprochen wird.

Foucault entwickelt in seinen Vorlesungen ausgehend von dieser konstitutiv freien und männlichen Figur des parrhesiastes und ausgehend von den Kynikern ein spezifisches, affirmativ verstandenes Verständnis der Philosophie als Mut zur Wahrheit. ${ }^{196}$ In seiner Darstellung dramatisieren und inszenieren Kyniker - für Foucault verkörpern sie die Grenze des philosophischen Diskurses - philosophische Prinzipien durch das Leben selbst.

des Subjekts konstruktiv aufnimmt, um davon ausgehend ein neues philosophisches Programm zu entwickeln.

194 Die Figur des »Mutes zur Wahrheit« wird von Foucault mit jener Form von Kritik kurzgeschlossen, die er mit der Aufklärung hervortreten sieht: Es handle sich dabei um ein ethos. Dieses ethos beinhalte eine Art philosophischen Fragens, die »zugleich die Beziehung zur Gegenwart, die geschichtliche Seinsweise und die Konstitution seiner selbst als autonomes Subjekt problematisiert« (Foucault 2007 [1994]: 182). Diese Beziehung verbinde uns mit der Aufklärung nicht mittels der »Treue zu den Elementen einer Lehre«, sondern vielmehr durch »die permanente Reaktivierung einer Haltung « (ebd.). Dieses philosophische ethos könne als eine »permanente Kritik unseres geschichtlichen Seins« (ebd.: 182) bestimmt werden. Zur Kritik als einer verkörperten Haltung siehe Dätwyler/Weibel 2015 .

195 Etymologisch bedeutet parrhesia »alles zu sagen« (von griech. pan (alles) und rhema (das Gesagte)).

196 Auf der einen Seite schafft Foucault also Argumentationsinstrumente und eröffnet Perspektiven, die es ermöglichen, den philosophischen Diskurs unter anderen, neuen Vorzeichen zu denken, nämlich im Zusammenhang mit Machtverhältnissen. Auf der anderen Seite reproduziert Foucault ein Denken, das auf Ausschlüssen basiert: Die zentrale und wichtige Bemerkung nämlich, dass das Wahrsprechen ganz bestimmten Personen vorbehalten ist, hat für Foucaults Verständnis der parrhesia und seinen Philosophiebegriff letztlich keine Konsequenzen. Beide Aspekte - die Generierung neuer Denkmöglichkeiten und die Reproduktion alter »hartgesottene[r]« Wahrheiten - laufen auch in aktuellen philosophischen Erneuerungen parallel. 
Der Kynismus, der sich in der konkreten Lebensweise einer Person äußert, sei also jene »Fratze, die die Philosophie sich selbst schneidet, jener gebrochene Spiegel, in dem der Philosoph sich zugleich sehen, aber nicht erkennen soll« (Foucault 2010 [2009]: 350). Mit seinem Rückbezug auf die griechische Philosophie begründet und legitimiert Foucault hier ein Verständnis der Philosophie, das die Lebensweise einer Person ins Zentrum des philosophischen Interesses rückt. Es hat zugleich die Funktion, die vorherrschende Philosophie zu spiegeln. »Die Kyniker stellen nämlich in ihrer ganzen Aggressivität den Moment dar, in dem die Selbstaskese nur noch den Wert hat, als Provokation an die anderen gerichtet zu werden, weil es darum geht, aus sich selbst ein Schauspiel zu machen, das jeden mit seinen eigenen Widersprüchen konfrontiert (Gros 2010 [2009]: 458). Die Figur des »Mutes zur Wahrheit« stelle eine von zwei historischen Gründungslinien von Kritik dar: In der einen Form, der »kynischen Modalität«, trete die Wahrheit durch die Lebensweise einer Person in Erscheinung und sei somit an den bios gebunden. Die andere Form, die "platonische Modalität«, sei nicht primär an das Leben, sondern vielmehr an den logos und somit an metaphysische Voraussetzungen gebunden. In der ersten Modalität werde Wahrheit durch ein »anderes Leben « (durch die Lebensweise einer Person) manifest, wohingegen in der zweiten Modalität Wahrheit gewissermaßen abstrakt-metaphysisch durch die Vorstellung einer »anderen Welt« hervorgebracht und somit entkörpert werde. Beide Bereiche treten gemäß Foucault in der konkreten Lebenswelt nicht getrennt voneinander auf, vielmehr seien sie konstitutiv miteinander verschränkt. Allerdings habe die platonische und in diesem Sinne metaphysische Modalität die sich an der Lebensweise orientierende Modalität im Laufe der Geschichte überlagert und verdeckt (ebd.: 320-323).

Diese von Foucault in seinen Vorlesungen lediglich skizzierten Überlegungen korrespondieren mit Seidels Zwangslage, dass nämlich Wahrheit, Geist und Bewusstsein einander bedingende Aspekte seien. Seidel denkt gegen die zweite, d.h. metaphysische Modalität an, ohne sie affirmativ zu überschreiten. Besonders eindrücklich wird dies im bereits zitierten Ende von Bewußtsein als Verhängnis: »Mögen die Waffen gegen das allein herrliche analytische Bewusstsein immer schärfer gespitzt werden und es an seinem eigenen Geiste zugrunde gehen - und wäre dieser sogar: die Wahrheit selbst « (Seidel 1927: 205). In der Rezeptionsgeschichte hingegen wird Seidel zu einer Figur, die in der ersten, in der »kynischen Modalität« zu verorten ist: Er wird - insbesondere im Zusammenhang mit seinem Suizid - zu einer tragischen Figur stilisiert, in der Leben und Werk deckungsgleich sind. Dadurch wird eine Form von Wahrheit hervorgebracht und verteidigt, die ihre Wirkung aus der Suggestion eines authentisch gelebten Lebens zieht. Wie im Kapitel zu Seidel 
ausgeführt wurde, wird in dessen Rezeptionsgeschichte deutlich, dass diese Form von Wahrheit allgemeinere Aussagen beansprucht: Seidel und sein Text werden - zeitdiagnostisch - als Exempel für eine spezifisch historische Situation rezipiert und interpretiert.

Inwiefern sich Foucaults kynische Kritik tatsächlich an der Figur Seidel festmachen lässt und ob dessen philosophische Selbstzerfleischung tatsächlich Foucaults platonischer Modalität entspricht, ist nicht entscheidbar. Unbestritten aber bleibt, dass die Figur Seidel in der diffizilen Mischung aus Person und Werk einen Kynismus verkörpert, der den Philosophen des frühen 2o. Jahrhunderts einen Zerrspiegel vorhält. 